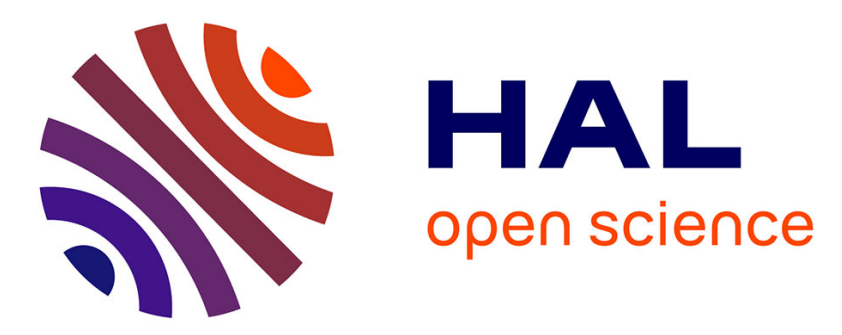

\title{
Modelling Transition And International Opening In Asia: The Case Of Vietnam With A Comparison With China And The "Asian Tigers"
}

Alain Sand-Zantman, Jean-Louis Brillet, Cuong Le Van, Jacques Mazier

\section{- To cite this version:}

Alain Sand-Zantman, Jean-Louis Brillet, Cuong Le Van, Jacques Mazier. Modelling Transition And International Opening In Asia: The Case Of Vietnam With A Comparison With China And The "Asian Tigers". Comparative Economic Studies, 2000, 42, pp.93-130. 10.1057/ces.2000.25 . halshs00372748

\author{
HAL Id: halshs-00372748 \\ https://shs.hal.science/halshs-00372748
}

Submitted on 2 Apr 2009

HAL is a multi-disciplinary open access archive for the deposit and dissemination of scientific research documents, whether they are published or not. The documents may come from teaching and research institutions in France or abroad, or from public or private research centers.
L'archive ouverte pluridisciplinaire HAL, est destinée au dépôt et à la diffusion de documents scientifiques de niveau recherche, publiés ou non, émanant des établissements d'enseignement et de recherche français ou étrangers, des laboratoires publics ou privés. 
Mars 2000

\title{
MODELLING TRANSITION AND INTERNATIONAL OPENING IN ASIA: \\ THE CASE OF VIETNAM WITH A COMPARISON WITH CHINA AND THE "ASIAN TIGERS"
}

\author{
Alain Sand-Zantman (Erudite-Université Paris 12 et CED-TEAM- \\ CNRS/Université Paris 1) \\ Jean Louis Brillet (INSEE, Département de la Coopération) \\ Cuong Le Van (CERSEM-CNRS /Université Paris 1) \\ Jacques Mazier (CEDI, Université Paris 13)
}

E-mail : sandzantman@univ-paris12.fn

We wish to thank Marie Lavigne for her useful comments, and Ahn Dao Tran for her help at the first steps of this work. A first draft of this paper has been presented at the panel "Vietnam's Economy in Transition", Association for Comparative Economic Studies, Allied Social Science Associations 2000 Annual Meetings, January 7-9, Boston, MA, USA 


\begin{abstract}
$\underline{\text { Abstract }}$
This paper describes the multisectoral macroeconomic model of a small developing economy in transition, in order to highlight linkages between agriculture and the rest of the economy, and consequences of external opening up. Agriculture is a supply sector, sticky in the short range with market clearing by price adjustment. The non agricultural sector is demand-led, with imperfect competition (and hence sticky prices and indexed nominal wages). According to this dual theoretical pattern, labor market is segmented with an unlimited supply in the rural area. This part of labor force is employed in the agricultural sector and in the rural non agricultural one. Urban workers are employed in the non agricultural sector but may face unemployment. The wage gap between urban and rural areas induces migration, according to a Harris Todaro mechanism.

This framework is applied to the Vietnam case. A calibrated quantitative model performs a base line simulation from 1993 to 2010, following approximately the path designed by the Vietnamese government. Finally, this model is used to sketch various scenarios, among which traditional macroeconomic packages, structural reforms, and external shocks.
\end{abstract}

\title{
Résumé
}

Cet article expose le modèle macroéconomique multisectoriel d'une petite économie en développement et en transition, visant à décrire l'interaction entre le secteur agricole et le reste de l'économie, et à analyser les conséquences d'un processus d'ouverture. L'offre agricole est rigide à court terme, le marché s'ajustant par variation des prix. Le secteur non agricole est un secteur de demande, caractérisé par une imperfection de la concurrence expliquant la rigidité des prix et des salaires. Selon le modèle dualiste traditionnel, le marché du travail est segmenté et l'offre de travail rurale illimitée. Une part de la force de travail rurale est employée dans le secteur rural non agricole, le reste trouvant à s'employer dans l'agriculture. La force de travail urbaine est soit employée par le secteur non agricole, soit en chômage. L'écart entre revenus urbain et rural provoque les migrations internes, selon un schéma à la "Harris Todaro".

Ce cadre d'analyse est appliqué l'économie du Vietnam. Une grande part des paramètres du modèle numérique sont obtenus par calibrages ou empruntés à la littérature. Un compte central est ensuite calculé pour les années 1993-2010 sur la base des prévisions officielles. Les simulations réalisées avec ce modèle permettent d'analyser les conséquences d'un certain nombre de chocs exogènes de politique macroéconomique, de réformes structurelles, ou de perturbations externes.

JEL. Classification : E17, 053, 027.

Mots clés: Vietnam, modélisation multisectorielle., développement, transition.

Keywords: Vietnam, multisectoral models, development, transition. 


\section{Introduction}

Like China, Vietnam displays three structural features:

- as a transition country, it aims to move from a closed socialist planned economy to an opening capitalist market-cleared one;

- as a poor developing country, it needs to build up capital and technology in order to catch up with more developed economies, and has to face sectoral and spatial restructuring with growing internal migrations;

- $\quad$ as willing to follow the "Asian way of modernization", the state claims to monitor a rather narrow opening up of the economy, and more generally the liberalization process.

Because of the extent of the structural changes which occurred since the beginning of the 1980s in Vietnam, and because of the lack of data, using an econometric model is illusory. Using a computable general equilibrium model describing structural changes in detail would be a huge and rather fragile work. Although CGE models can capture short-term rigidities, they are not well suited to the Vietnam case, which is characterized by unemployment and the lack of full-fledged market clearing mechanisms. The proposed model is an aggregate one, focusing on agricultureindustry linkages which will not be estimated but will be calibrated and used for simulations.

Inspired of Alain Sand-Zantman and alii (1999a and b), the two-sector model presented in this article aims at capturing some consequences of the process of modernization and liberalization. Thus:

- the inelastic agricultural sector (sector 1) supplies domestic and foreign demand, with a market clearing mechanism through price adjustments;

- the non agricultural sector (sector 2) produces an imperfect substitute of a foreign importable good. This demand-led sector supplies both domestic and foreign markets. The output price is set according to a mark-up over unit cost including input and labor costs. The input-output linkages are fully described.

- due to external opening, both goods are exported and the domestic demand for the non agricultural good is provided by domestic activities and imports. Foreign direct investment in sector 2 supplement domestic investment in both sectors.

- the introduction of new technologies is exogenous in sector 1 but endogenous in sector 2 , depending on domestic and above all on foreign direct investment.

- agricultural sector 1 is naturally a rural one, but non agricultural sector 2 is present in rural and urban areas. The distribution of good 2 manufacturing between both areas is weakly elastic to the urban/rural wage differential;

- the labor market is dualistic. The urban wage adjusts with respect to prices, productivity, and urban unemployment. The rural wage in sector 2 determines the agricultural income (supposed to be equal to agricultural value added per rural worker);

- rural/urban migrations are explicitly modeled, following a Harris-Todaro mechanism (Harris, J. and Todaro, M., 1976 and for a survey Sand-Zantman, A., 1991 and Ray, D. 1998), with flows depending on the expected urban/rural wage differential.

Though numerous mechanisms of substitution and flexibility are built in the model - on goods, labor and capital markets - our framework keeps some of the main 
rigidities that according to the Structuralist School explain bottlenecks and chronic inflation in less developed countries (see Kalecki, M., 1976, Cardoso, E., 1981, Rattso, J., 1989 and Basu, K., 1997).

The complete analytical model is not tractable, which requires numerical developments and simulations. However, some underlying mechanisms are modeled, with the help of a very simple formalization.

The numerical model is calibrated on the basis of Vietnamese data for the period 1989-1997. Moreover, numerous parameters come from the literature. An ex-post forecast is computed in order to check that the model replicates some of the main features of the years 1993-1997, using policy and exogenous variables observed during this period and residual adjustments when necessary. A base line forecast is computed for 1997-2010, designing an economic path consistent with targeted indicators planned by Vietnamese authorities.

The paper then presents two sets of simulations. A first set of analytical simulations aims to assess the consequences of elementary supply and demand shocks. These simulations are used to get a better understanding of the model properties and to estimate its sensitivity to the main calibrated parameters. A second set combines the elementary shocks in order to explore the impact of the dramatic changes recently faced by Vietnam and China:

- $\quad$ the "Asian" transition is based on the combination of increasing domestic saving and investment, and a strictly monitored trade opening up, in order to speed up capital accumulation and modernization.

- a second scenario presents a more liberal growth strategy whereby modernization is backed on foreign investment, as experimented in the new generation of "Asian tigers" (Malaysia, Thailand, Philippines...): China, likewise, relies on foreign direct investment as a driving force in numerous sectors.

- finally, we analyze the impact of the "Asian Crisis" on the Vietnamese economy in the end of the 1990s.

The paper is organized as follows. A first section presents the structure of the model. Using a simple static framework, the second section analyzes the consequences of the inelastic supply in the agricultural sector on relative price determination, macroeconomic adjustment, and on the migration process. The third section presents the central forecast for the period 1993-2010, and the outcomes of the elementary simulations. The fourth and last section focuses on the three scenarios mentioned above, transition, modernization through foreign investment, and the impact of the Asian crisis.

\section{The model}

The model includes an agricultural sector (sector 1) which production is rigid, and a non agricultural sector, consisting mainly of industry and services (sector 2), which is demand-led. The agricultural production, at constant prices, is determined by a constant capital productivity and a capital rate of accumulation that is also exogenous. The market clears through lagged price adjustments, which allows for an analysis of the consequences of the rigidities in the agricultural supply. To these basic mechanisms one has to add price determination in sector 2 , implying a linkage through unit costs (input and labor costs), which provides for an endogenous determination of the domestic terms of trade between agriculture and the rest of the economy. The importance of the agricultural sector (around $30 \%$ of the value added 
in the beginning of the 1990s in Vietnam and China) has been underlined in most of the studies on the Asian transition (Le Van, C. and Mazier, J., 1998, and Lavigne, M., 1999). Early and extensive reforms in this sector are regarded as key factors in explaining both how an output decline has been avoided and how disinflation has been successfully achieved in the Asian transition economies (Kalra, S., and Slok, T.,1999).

\section{Supply}

- Sector 1 capital stock :

(1.1) $k_{1}=k_{1}(-1) .\left(1-\bar{\delta}_{1}\right)+i_{1}$ with $0<\bar{\delta}_{1}<1$ as the capital depreciation rate,

- Sector 1 production capacity :

(1.2) $q_{1}^{*}=\bar{\chi}_{1} k_{1}(-1)$ with " $\bar{\chi}_{1}$ " for the capital productivity in agriculture. (Actual output " $q_{1}$ " equalizes production capacity " $q_{1}$ ")

- Sector 1 investment :

(1.3) $i_{1}=\bar{\lambda}_{1} k_{1}(-1)$ with " $\bar{\lambda}_{1}$ " as the accumulation rate in agricultural sector,

In the demand-led sector 2, the production capacity depends on an endogenous capital productivity, which is a function of domestic and foreign investment. The investment behavior embodies a flexible accelerator, and capital accumulation decreases with rising idle capacity. FDI are also introduced as part of the total investment, but only in sector 2 .

- Sector 2 capital stock :

(1.4) $k_{2}=k_{2}(-1) .\left(1-\bar{\delta}_{2}\right)+i_{2} \quad$ with $0<\bar{\delta}_{2}<1$, as the capital depreciation rate,

- Sector 2 production capacity:

(1.5) $q_{2}^{*}=\chi_{2} k_{2}(-1)$ with " $\chi_{2}$ " as the capital productivity in the non agricultural sector.

- Sector 2 capital productivity:

(1.6) $\chi_{2}=\chi_{2}(-1) .\left(1+\hat{\chi}_{2}\right)$ with " $\hat{\chi}_{2}$ " for the growth rate of capital productivity in sector 2.

(1.7) $\hat{\chi}_{2}=\gamma_{k}^{f} \hat{k}_{2}^{f}(-1) \quad$ with " $\hat{k}_{2}^{f}$ " for the growth rate of capital from abroad due to foreign investment.

- Sector 2 investment :

(1.8) $i_{2}=i d_{2}+\overline{i e}_{2}$ with " $\overline{i e}_{2}$ " for exogenous foreign direct investment in sector 2 , (noted FDI).

- Domestic investment :

(1.9) $\frac{i d_{2}}{k_{2}(-1)}=\lambda_{20}\left(\frac{i d_{2}}{k_{2}(-1)}\right)+\lambda_{21}\left(\frac{v a_{2}}{v a_{2}(-1)}-1\right)+\lambda_{22} \frac{u_{2}}{\overline{u_{2} \max }}+\lambda_{23}$ with "va $a_{2}$ for the sector 2 real value added, " $u_{2}$ " and " $u_{2} \max$ " respectively for the actual and maximum utilization rates of production capacities. 
- Utilization rate of production capacity in the non agricultural sector :

(1.10) $u_{2}=\frac{q_{2}}{q_{2}^{*}}$

\section{Demand and output prices}

The model determines agricultural price in two steps:

- first, a market clearing process determines an equilibrium "shadow" price, assuming the export price to be equal to the domestic production price and to the domestic demand price (the model excludes agricultural imports).

- second, effective domestic demand and exports are function of a lagged price. At this price, the gap between (effective) external and internal demands, and supply entails adjustment of agricultural inventories.

- Equilibrium market price in agriculture:

(1.11) $p_{1 e}=\left(x_{1 e} \cdot p_{1 e}+d i_{1 e} \cdot p d i_{1 e}\right) / q_{1}^{*}$ with " $p_{1 e}$ "for output "shadow" price, " $x_{1 e}$ " and "di $i_{1 e}$ " respectively for "notional" exports and domestic (intermediate and final) demand of agricultural good at shadow domestic demand price index "pdi $i_{1 e}$ ".

(1.12) $p d i_{1 e}=p_{1 e}$

- Actual production and (intermediate and final) consumption prices in agriculture, and inventories:

(1.13) $p_{1}=\alpha_{1} \cdot p_{1 e}+\left(1-\alpha_{1}\right) \cdot p_{1}(-1)$

(1.14) $p d i_{1}=p_{1}$

(1.15) stock $k_{1}=q_{1}^{*}-\left(d i_{1}+x_{1}\right)$ with "stock ${ }_{1}$ "for change in agricultural inventories, "di $i_{1}$ "for effective domestic (intermediate and final) demand of the agricultural good at the domestic demand price index "pdi $i_{1}$, and " $x_{1}$ " for actual agricultural exports,.

The price of sector 2 output is set according to a mark up over total unit cost, including input and labor costs, with a negative influence of idle capacity.

- $\quad$ Targeted output price in sector 2 :

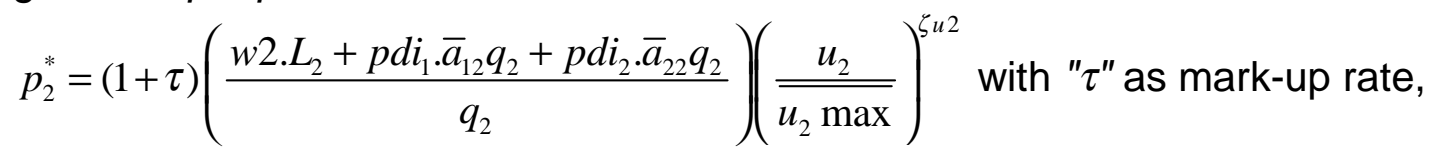

" $\zeta u 2$ " for elasticity of targeted price to a change in utilization rate of production capacity . "w2" and " $\mathrm{L}_{2}$ " are respectively the weighted average of rural and urban wages and the labor force in sector 2 , while "pdi 2 " is a weighted index price of domestic demand.

- Effective output price in non agricultural sector:

$$
p_{2}=\exp \left[\alpha_{2} \log \left(p_{2}^{*}\right)+\left(1-\alpha_{2}\right) \log \left(p_{2}(-1)\right)\right]
$$




\section{Final demand}

Household consumption depends on the labor income in sector 2 (the labor force is considered here as earning an urban or a rural wage whatever the status of the workers - independent/wage-earners, and formal/informal workers), and on the unearned incomes in the agricultural and non-agricultural sectors, with respective consumption propensities of 0.95 and 0.7 . Non-labor incomes are obtained by difference from the total value added. Consumption is divided between agricultural and non agricultural goods according to a log-linear expenditure equation function of income, and of relative prices for the two products. Investment by the firms has already been presented; it has a domestic component and a foreign one (FDI).

Exports of agricultural goods increase with domestic output and price competitiveness. These exports are strongly price elastic, and according to the small country hypothesis, foreign demand is assumed to be unlimited. Agricultural goods are not imported, an assumption validated by the Vietnamese data. Exports and imports functions of non agricultural goods are more standard. Both depend on price competitiveness and idle capacity. Exports increase with foreign demand and imports with domestic demand. Foreign prices and the nominal exchange rate are exogenous.

- Global consumption :

(1.18) $c m=\overline{c w} \frac{w 2 . L_{2}}{p d i}+\overline{c R} \frac{R \text { ' }}{p d i}$ with " $\overline{c w}$ " and " $\overline{c R}$ " respectively for consumption propensity of labor income in sector 2 and other incomes $R$ ', and "pdi" as the weighted index price of domestic demand.

- Consumers trade-off between agricultural and non agricultural sectors :

(1.19) $c m_{1}=\overline{c m}_{1}+\bar{c} \cdot\left(c m-\overline{c m}_{1}\right)^{\eta_{1}} \cdot\left(\frac{p d i_{1}}{p d i_{2}}\right)^{-\eta_{2}}$ with " $\overline{c m}_{1}$ " for minimum consumption of

good 1 , and " $\eta_{1}$ " and " $\eta_{2}$ ", for demand elasticity of good 1 respectively to the "discretionary" part of the consumption budget, and to the relative domestic demand price index.

(1.20) $\mathrm{cm}_{2}=\mathrm{cm}-\mathrm{cm}_{1}$

- Agricultural exports :

$x_{1}=\bar{x}_{1} \cdot q_{1}^{*} \cdot\left(\frac{\overline{\text { pet }} \cdot \overline{d o n g}}{p_{1}}\right)^{\varepsilon x_{1}} \quad$ with " $\varepsilon x_{1}$ " being the price elasticity of exports, and respectively $\overline{p e t}$ and $\overline{d o n g}$ the foreign price index and the exchange rate index.

- Non agricultural exports :

Idle capacity is entered as an argument in the imports and exports equations of non agricultural goods. The opening up of the Vietnamese economy is built in export and import functions through two exogenous trends, " $e^{\text {touv } 2 \text { " }}$ and " $e^{\text {touvm } 2 \text { " multiplying }}$ respectively the exogenous foreign demand of exports " $\overline{d m 2}$ " and the domestic 
demand of non agricultural good " $\mathrm{di}_{2}$ ". After a significant shock at the beginning of the period, "touvx2" and "touvm2" are slowly scaling down.

$$
x_{2}=\bar{x}_{2} \cdot \overline{d m_{2}} \cdot\left(\frac{u_{2}}{\overline{u_{2} \max }}\right)^{\varepsilon u x 2} \cdot\left(\frac{\overline{\text { pet }} \cdot \overline{d o n g}}{p_{2}}\right)^{\varepsilon x_{2}} \text { with " } \varepsilon u x 2 \text { " as the elasticity of exports }
$$

to a change in the utilization rate of production capacity, and " $\varepsilon x_{2}$ " as the relative price elasticity of exports.

- Non agricultural imports :

(1.23) $m_{2}=\bar{m}_{2} . o d i_{2} \cdot\left(\frac{u_{2}}{\overline{u_{2} \max }}\right)^{\varepsilon u m 2} \cdot\left(\frac{\overline{\text { pet. }} \cdot \overline{\text { dong }}}{p_{2}}\right)^{-\varepsilon m 2}$ with " $\varepsilon u m 2$ " as elasticity of imports to a change in utilization rate of production capacity, and " $\varepsilon m_{2}$ " as relative prices elasticity of imports.

\section{Employment, sector and spatial distribution of labor demand, and wages.}

The model embodies various kinds of linkages between urban and rural labor markets:

- Targeted labor demand of non agricultural sector 2 depends on both the level of product demand and the endogenous labor productivity. In the short term, error correction approach is used to model adjustment delays relatively to the targeted level of employment.

- Production is divided between urban and rural firms and public institutions: thus the targeted distribution of employment is slightly sensitive to the urban/rural wages ratio in sector 2 , with a sector 2 rural wage equal to the agricultural one. Adjustment delays to the targeted spatial distribution of production between urban and rural areas are modelled incorporating also an error correction form.

- Labor productivity, lagged price indexing, urban unemployment and the share of labor income in urban sector 2 value added explain wage setting in the urban sector 2 . The scarcity of qualified labor force justifies the indexing of real wages on productivity in the urban sector. Urban unemployment reduces the wageearners pressure. But a decreasing share of labor income in urban value added rises urban wage claims. Thus, income distribution plays a balancing role on wage determination.

- For agriculture, we assume unlimited labor supply and no wage earners. The sum of individual incomes amounts to the agricultural value-added.

- Targeted labor productivity in the non agricultural sector:

(1.24) $\pi_{2}^{*}=\pi_{2}^{*}(-1)\left(1+\hat{\pi}_{2}\right) \quad$ with $\hat{\pi}_{2}$ for the growth rate of targeted labor productivity.

(1.25) $\hat{\pi}_{2}=\gamma_{l}^{d} \hat{k}_{2}^{d}+\gamma_{l}^{f} \hat{k}_{2}^{f}+\bar{\pi}_{2} \quad$ with $\hat{k}_{2}^{d}$ and $\hat{k}_{2}^{f}$ for the respective growth rates of domestic and foreign capital, and $\gamma_{l}^{f}>\gamma_{l}^{d}>0$.

- Targeted employment in the non agricultural sector :

(1.26) $L_{2}^{*}=\frac{q_{2}}{\pi_{2}^{*}}$ 
- Targeted distribution of labor demand between urban and rural areas in non agricultural sector 2 :

(1.27) $L_{2 u}^{*} / L_{2 c}^{*}=\exp \left[v_{1} \cdot \log (\right.$ relw $\left.)+v_{2} \cdot \log \left(L_{2 u}(-1) / L_{2 c}(-1)\right)+v_{3}\right]$ with " $L_{2 u}^{*}$ " and " $L_{2 c}^{*}$ " for targeted urban and rural labor demand, "re/w " for the urban/rural wage ratio, and $" v_{1} "<0$.

- Urban/rural wage ratio:

(1.28) relw $=w_{2 u} / w_{2 c}$

- Actual employment in the non agricultural urban sector :

(1.29) $L_{2 u}=\exp \left[v_{4} \log \left(L_{2 u}(-1)\right)+\left(1-v_{4}\right) \log \left(L_{2 u}^{*}\right)\right]$

- Actual employment in non agricultural rural sector :

(1.30) $L_{2 c}=L_{2 c}^{*}$

- Actual total employment in sector 2:

(1.31) $L_{2}=L_{2 u}+L_{2 c}$

- Actual labor productivity in the non agricultural sector:

(1.32) $\pi_{2}=\frac{q_{2}}{L_{2}}$

- Urban wage setting

(1.33) $\frac{w_{2 u}}{w_{2 u}(-1)}=\left(\frac{p d i}{p d i(-1)}\right)^{\xi_{1}}\left(\frac{p d i(-1)}{p d i(-2)}\right)^{1-\xi_{1}}+\left(\frac{\pi_{2}}{\pi_{2}(-1)}\right)+\xi_{2} \cdot U+\xi_{3} \cdot\left(\theta-\theta^{*}\right)+\varpi$ with

$U=\left(L_{2 u}-L_{u}^{s}\right) / L_{u}^{s}$ for urban unemployment rate $\left(L_{u}^{s}\right.$ meaning urban labor supply, as

explained below), $\theta=\frac{w 2 u . L 2 u}{v a u v 2}$ for the share of labor income in urban value added (and "vauv2" for nominal urban value added), $\theta^{*}$ for a "long run equilibrium share of wages in value added, $\xi_{2}<0$, and $\xi_{3}<0$.

- Agricultural income

(1.34) $w_{1}=v a v 1 / L_{1}$ with "vav1" for nominal agricultural value added.

- Non agricultural wage in rural area:

(1.35) $w_{2 c}=w_{1}$

\section{Labor supply and rural/urban migrations}

Changes in rural and urban labor supply are determined by the respective natural rates of demographic growth, corrected by the exogenous urban and rural

\footnotetext{
${ }^{1}$ We assume a long run rate of $2 / 3$ for the labour share in value added, (like in the developed economies).
} 
activity rates of population, and by the endogenous migrations ${ }^{2}$. Urban unemployment results from the difference between urban labor demand and supply.

Migrations depend on the expected urban/rural wage differential (with the expected urban wage equalizing the actual urban wage multiplied by the probability of getting a job). Migrations decrease the rural labor supply and increase the urban one. As migrations feed urban unemployment, they curb the bargaining power of urban wage earners... and diminish the expected payback of future migrations!

- Labor supply on rural labor market:

(1.36) $L_{c}^{s}=L_{c}^{s}(-1) *(1+$ tdemc $)-m i g(-1)$ with "tdemc" for exogenous natural rural demographic growth rate, and "mig" for endogenous migrations.

- Labor supply and demand in agriculture:

We assume that the rural labor force not employed in rural sector 2 works in agriculture, following the traditional "dualistic" scheme.

(1.37) $L_{1}=L_{c}^{s}-L_{2 c}^{s}$

- Labor supply on urban labor market:

(1.38) $L_{u}^{s}=L_{u}^{s}(-1) *(1+t$ demu $)+m i g(-1)$ with "tdemu" for the exogenous natural urban demographic growth rate.

- Migration function:

(1.39) $\mathrm{mig}=$ tmig $* L_{c}^{s}$

$(1.40)$ tmig $=\overline{\text { tmig }} .\left[(1-U) \cdot\left(\frac{\left(w_{2 u}-w_{1}\right)}{w_{1}}\right)\right]^{\psi}$ meaning that migration rate is a function of the expected urban/rural wage differential (with $(1-U)$ for the probability of getting an urban job).

The rest of the model is very succinct. Endogenous taxes reach $95 \%$ of exogenous public expenditures. The monetary and financial system is not described. The model has 65 independent equations and identities and 65 endogenous variables : $k_{1}, i_{1}, q_{1}{ }^{*}, q_{1}, v_{1}, \operatorname{vav}_{1}, k_{2}, i_{2}, i d_{2}, q_{2}{ }^{*}, q_{2}, u_{2}, v_{2}, \operatorname{vav}_{2}, \operatorname{vauv}_{2}, \chi_{2}, \hat{\chi}_{2}, \hat{k}_{2}^{d}, \hat{k}_{2}^{f}$, $i$, va, vav, $p_{1 e}, p d i_{1 e}, d i_{1 e}, p_{1}, p d i_{1}, x_{1 e}$, stock1, $p_{2}^{*}, p_{2}, p d i_{2}, p d i, c m_{1}, c m_{2}, c m, d i_{1}$, $d i_{2}, x_{1}, x_{2}, m_{2}, \pi_{2}^{*}, \pi_{2}, \hat{\pi}_{2}, L_{1}, L_{2}{ }^{*}, L_{2}, L_{2 u}{ }^{*}, L_{2 u}, L_{2 c}{ }^{*}, L_{2 c}, r e l w, R, w_{1}, w_{2}, w_{2 u}, w_{2 c}, U$, $\theta . L_{c}^{s}, L_{u}^{s}$, tdemu, tdemc, mig, tmig.

In spite of its simplicity, it is not possible to perform an analytical solution of this model. However, before we present the outcome of quantitative simulations, a very simplified version can be used, focusing on the questions of price determination and rigidities in the supply sector.

\section{A simplified two-sector model and price determination in the supply sector}

In this static and simplified version, prices are supposed to be exogenous in sector 2 in order to focus on price adjustment between demand and supply in sector 1 . Total

\footnotetext{
${ }^{2}$ In this model, respective demographic growth rates and activity rates are equal, because lack of specific data.
} 
consumption depends on the distributed income, taken equal to the overall value added. The modeling of foreign trade is simplified, using export and import rates as a function of price competitiveness.

(2.1) $\bar{q}_{1}=a_{11} \bar{q}_{1}+a_{12} q_{2}+c m_{1}+x_{1} \quad$ with $a_{i j}$ as input-output coefficients.

(2.2) $q_{2}+m_{2}=a_{21} \bar{q}_{1}+a_{22} q_{2}+c m_{2}+i+\bar{g}+x_{2}$

(2.3) $\quad i=\overline{i_{1}}+\mu\left(q_{2}-q_{2(-1)}\right)$

(2.4) $\quad c m=c\left(\left(1-a_{11}-a_{21}\right) \cdot \bar{q}_{1}+\left(1-a_{22}-a_{12}\right) \cdot q_{2}\right)$

(2.5) $\quad \mathrm{cm}=\mathrm{cm}_{1}+\mathrm{cm}_{2}$

(2.6) $c m_{1}=\overline{c m_{1}}+\psi \cdot\left(c m-c m_{1}\right)^{\eta_{1}}\left(p_{1} / \bar{p}_{2}\right)^{-\eta_{2}}$ where $\eta_{1}>0$ and $\eta_{2}>0$.

(2.7) $\quad x_{1}=x_{1}\left(p_{1}^{*} \cdot e / p_{1}\right) \cdot \bar{q}_{1}$

(2.8) $\quad x_{2}=x_{2}\left(p_{2}^{*} \cdot e / \bar{p}_{2}\right) \cdot q_{2}$

(2.9) $m_{2}=m_{2}\left(p_{2}^{*} \cdot e / \bar{p}_{2}\right) \cdot q_{2}$

with $x_{1}^{\prime}>0, x_{2}^{\prime}>0, m_{2}^{\prime}<0$.

Equations (2.1), (2.4), (2.6) and (2.7) yield the supply-demand equilibrium for product 1 , which can be reduced to equation (2.11) and represented by curb $O$.

(2.10) $\bar{q}_{1} \cdot\left(1-a_{11}\right)=a_{21} \cdot q_{2}+\overline{c m_{1}}+\psi \cdot\left(c m-c m_{1}\right)^{\eta_{1}}\left(p_{1} / \bar{p}_{2}\right)^{-\eta_{2}}-x_{1} \cdot\left(p_{1}^{*} \cdot e / p_{1}\right)$

leading to :

(2.11) $p_{1}=O\left(q_{2}, e\right)$.

This increasing relation between $Q 2$ and $p 1$ can be easily interpreted. An increase in production 2 leads to more income distributed and to a growing demand. Facing a rigid supply, the rise in consumption of product 1 creates tensions which result in a price increase. In the same way a devaluation results in a demand-led recovery through export and creates the same type of tightening in sector 1.

with $\frac{\partial O}{\partial q_{2}}>0, \frac{\partial O}{\partial e}>0$ 


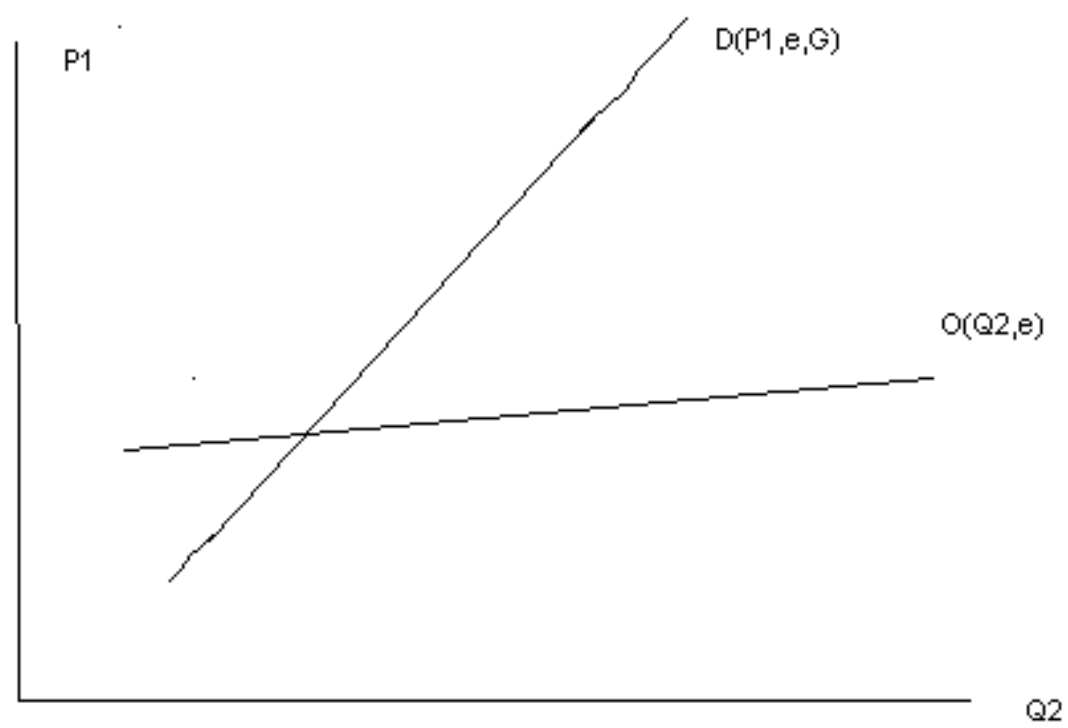

Figure 1: Supply and demand balances in a two-sector model

Equations (2.2), (2.3), (2.4), (2.5), (2.6), (2.8), and (2.9), yield the supply-demand balance of product 2, which can be reduced to equation (2.12) and represented by curb D.

(2.12) $q_{2}=D\left(p_{1}, e, \bar{g}\right)$,

with $\frac{\partial D}{\partial p_{1}}>0, \frac{\partial D}{\partial e}>0, \frac{\partial D}{\partial \bar{g}}>0$

This relation between $\mathrm{p} 1$ and $\mathrm{Q} 2$ is also increasing and can be easily interpreted. An increase in the price $\mathrm{p} 1$ of product 1 leads to a reduction of the consumption of product 1 and to a substitution of product 1 by product 2 , which production is stimulated. In the same way an increase of public expenditure or a devaluation leads to a demand-led recovery and to a rise of the production 2, in accordance with the Keynesian multiplier in the sector 2.

The resolution of the short-term equilibrium of the model can thus be reduced to two increasing relations between Q2 and p1 (equations (2.11) and (2.13)), which simultaneously yield the level of production Q2 of the demand-led sector 2 and the level of price $\mathrm{p} 1$ of the supply sector 1 (see figure 1).

The slope of the equation describing the equilibrium of product 1 (curb $\mathrm{O}$ ) is smaller than the slope for product 2 (curb D). It can be proved, in an intuitive way. If it was not the case, and if the curb $D$ was less steep than the curb $O$, an increase in public expenditure would shift the curb D to the right and lead to a decrease of $p 1$ and Q2, which is not realistic. 


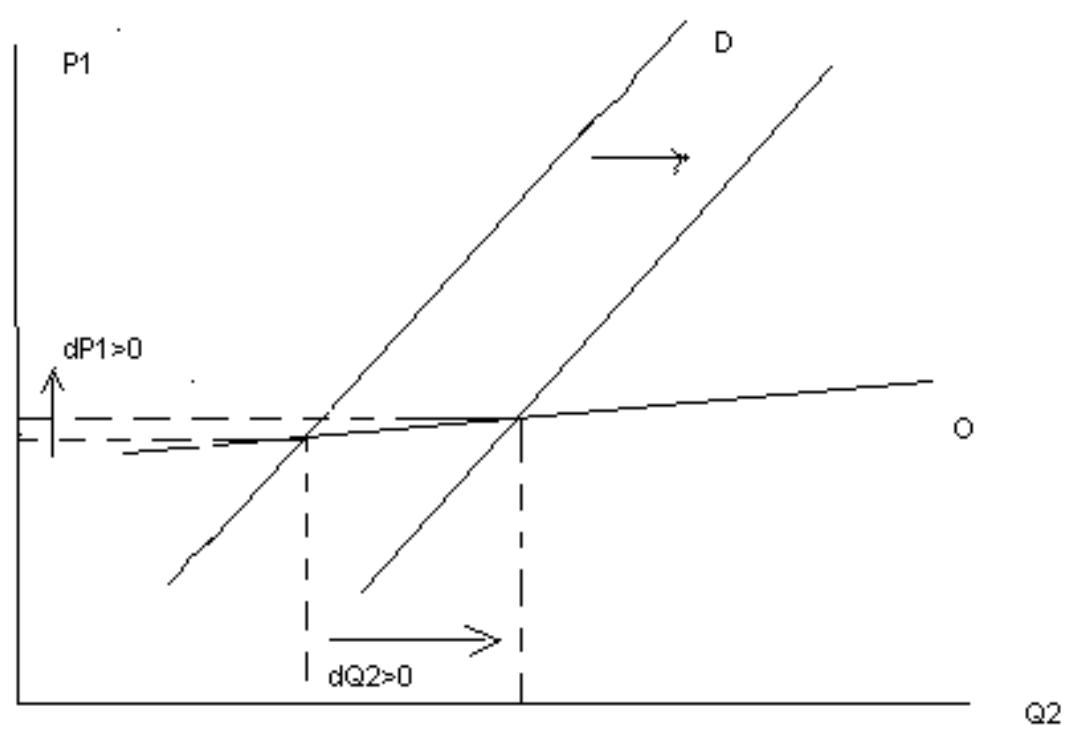

Figure 2: The impact of an increase in public expenditure

Two elementary shocks may illustrate the working of the model.

- An increase in public expenditure $(d G>0)$ shifts the curb $D$ to the right, leaving the curb $O$ unchanged (figure 2). The production Q2 rises, as well as the prices $\mathrm{p} 1$. The demand-led recovery stimulates the production of sector 2 in accordance with the Keynesian multiplier, while the production Q1 remains unchanged. The growth of distributed income leads to an increase of demand for both products. Due to a rigid supply in sector 1 , a tightening appears on the market of product 1 and results in an increase of the price for product 1.

- A devaluation (de>0) shifts also the curb $D$ to the right but raises the curb $O$ (figure 3). The price p1 rises, as well as the production Q2. The devaluation improves the price competitiveness and stimulates exports of both products. As the supply of sector 1 is rigid, this leads to a tightening on the market of product 1 and to an initial increase of price p1. Simultaneously, the export-led recovery in sector 2 leads to a growth of production Q2 and to an increase of the distributed income. The consumption of both products rises. As the supply of sector 1 is constant, this results in another factor of price increases for product 1 . These mechanisms simply illustrate how the traditional limits of a devaluation are amplified when facing rigidities in a supply sector. 


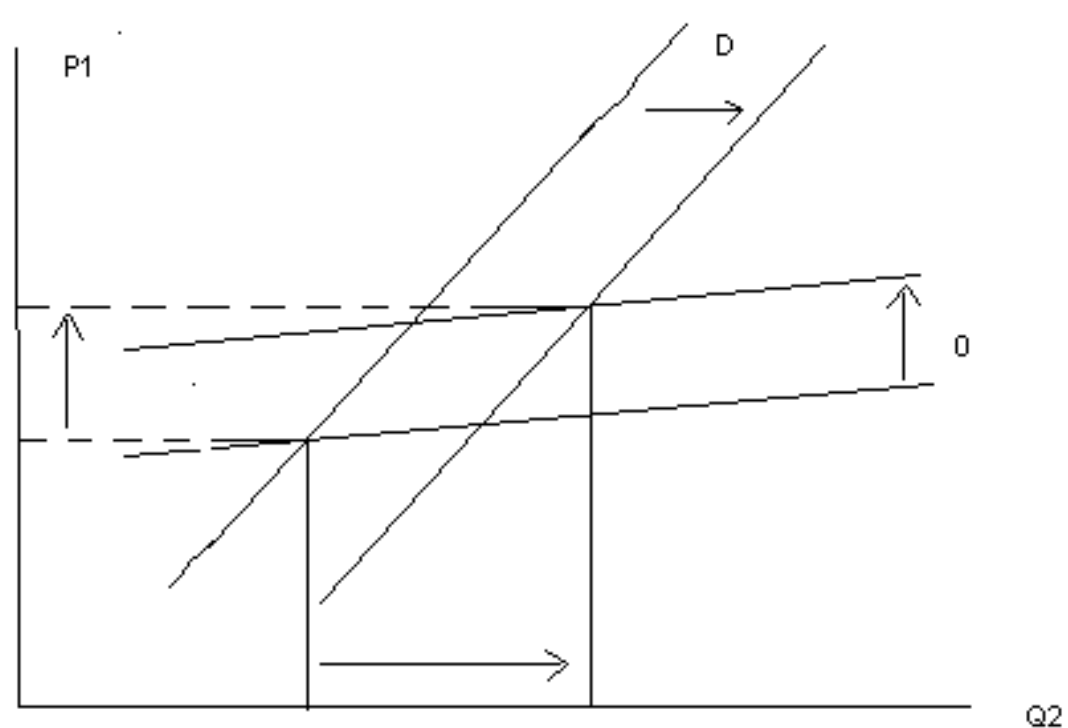

Figure 3: The impact of a devaluation

What can we say about labor market and migrations? In the case of an increase in public expenditure, a higher production in sector 2 entails less urban unemployment, and hence a higher expected urban wage. Simultaneously, price hikes on the agricultural market increase the rural income. Thus the impact on migrations is indeterminate.

In the case of a devaluation, the outcome is more complex. Devaluation increases agricultural prices and rural income. Export growth in both sector 1 and 2 results in an improvement of employment in sector 2, as it increases the expected urban wage. The former effect curbs migrations, while the latter encourages it, particularly if urban wages are very elastic to the consumer prices index. Thus, the outcome is also indeterminate.

This model is of course too static and oversimplified. Its main interest is to underline some simple linkages between price adjustment in the supply sector and the demand-led sector. These mechanisms will remain in the full model but will be supplemented in many respects.

\section{Making simulations}

\section{The base line path}

In a first stage, a consistent Vietnamese data base was built for the period 19891997, so as to perform a calibration of the model. Due to the lack of information, it aims at replicating first and foremost the data base of 1993. In a second stage, the model is used to calculate an ex-post forecast for 1993-1997 and an ex-ante forecast for the years 1998-2010. Finally, a comprehensive set of scenarios are simulated. 
For the ex-post simulation, the model runs a pluri-annual forecast, with residual adjustments allowing us to fit the historical trends. The ex-ante forecast is performed in a "step by step" process: thus, each annual base account is built using the numerical output of previous computations, following projections of exogenous variables from 1998 to 2010. So as to forecast a sensible path and to avoid untraceable collapses for the transition from ex-post data to ex ante forecasts, we keep on adjusting "add factors". Obviously, these residuals are gradually scaled down until the terminal period.

Figures 4 to 7 display the main features of these forecasts, with a plausible output growth rate of about $7 \%$, an inflation rate of $4 \%$, and an investment ratio of $29 \%$.

Base line simulations : 1993-2010

Figure 4: GDP and sectorial value-added growth rates

(1993-2010)

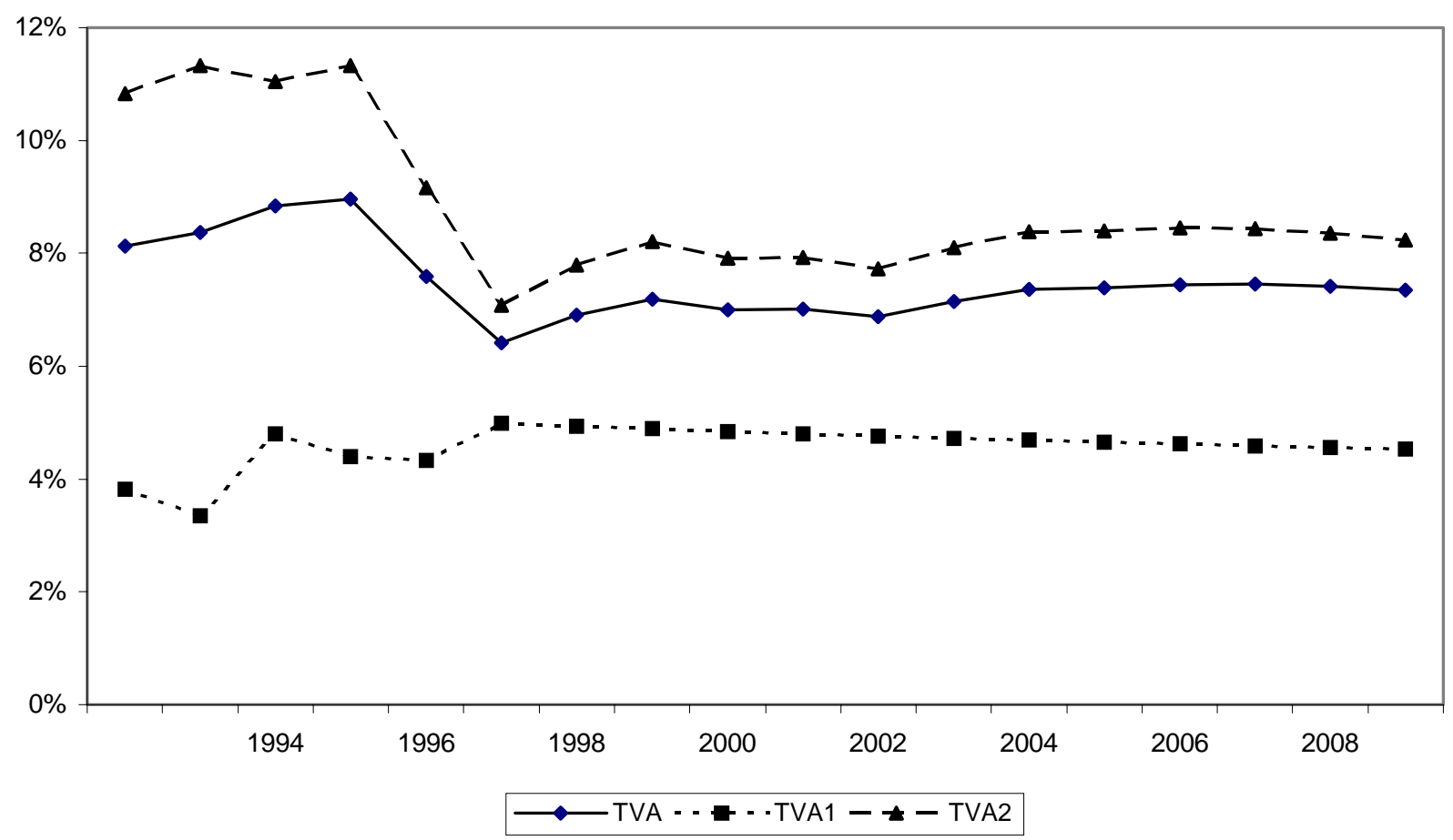


Figure 5: Growth rate of investment

(1993-2010)

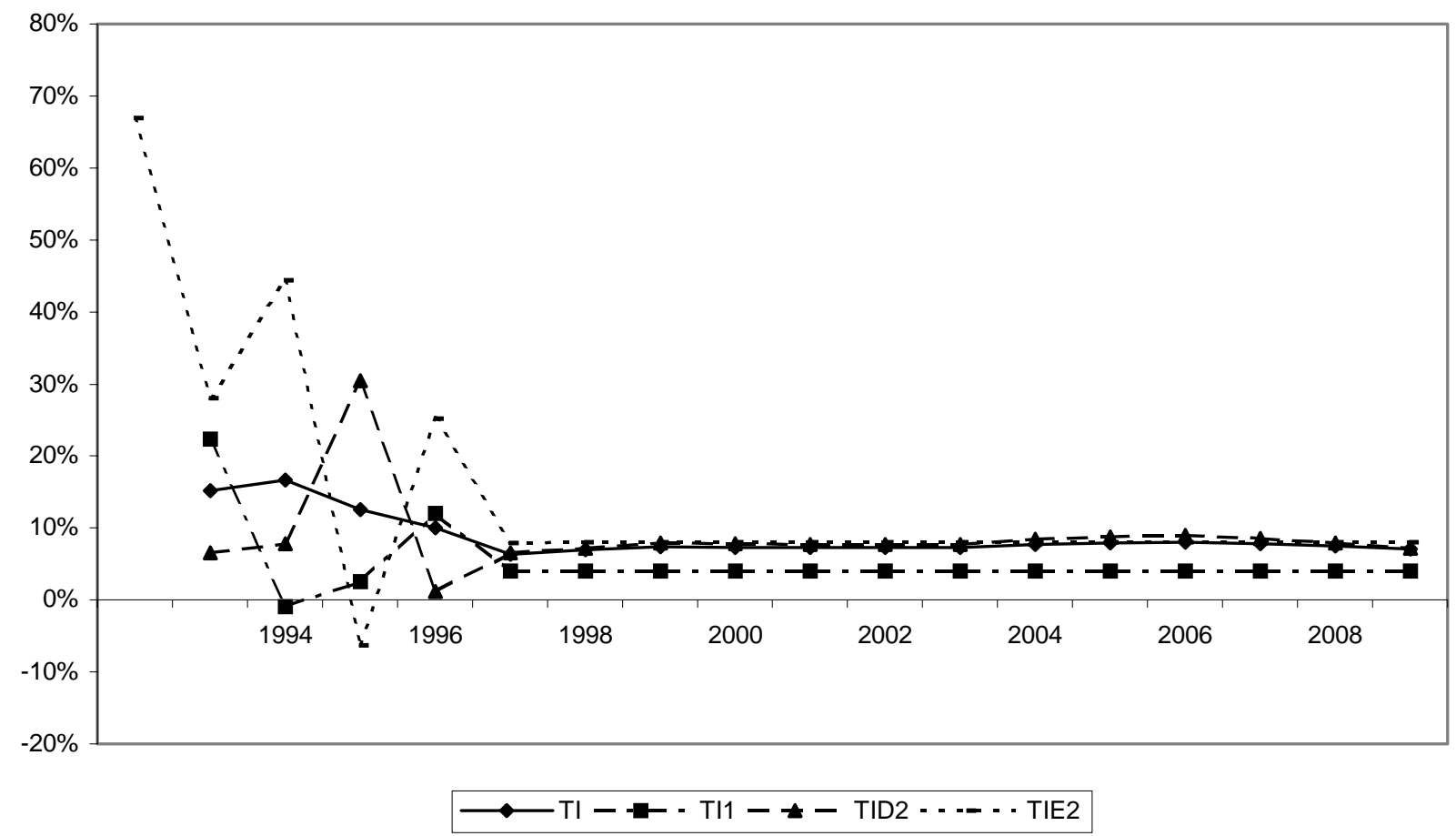

Figure 6: Inflation rates

(1993-2010)

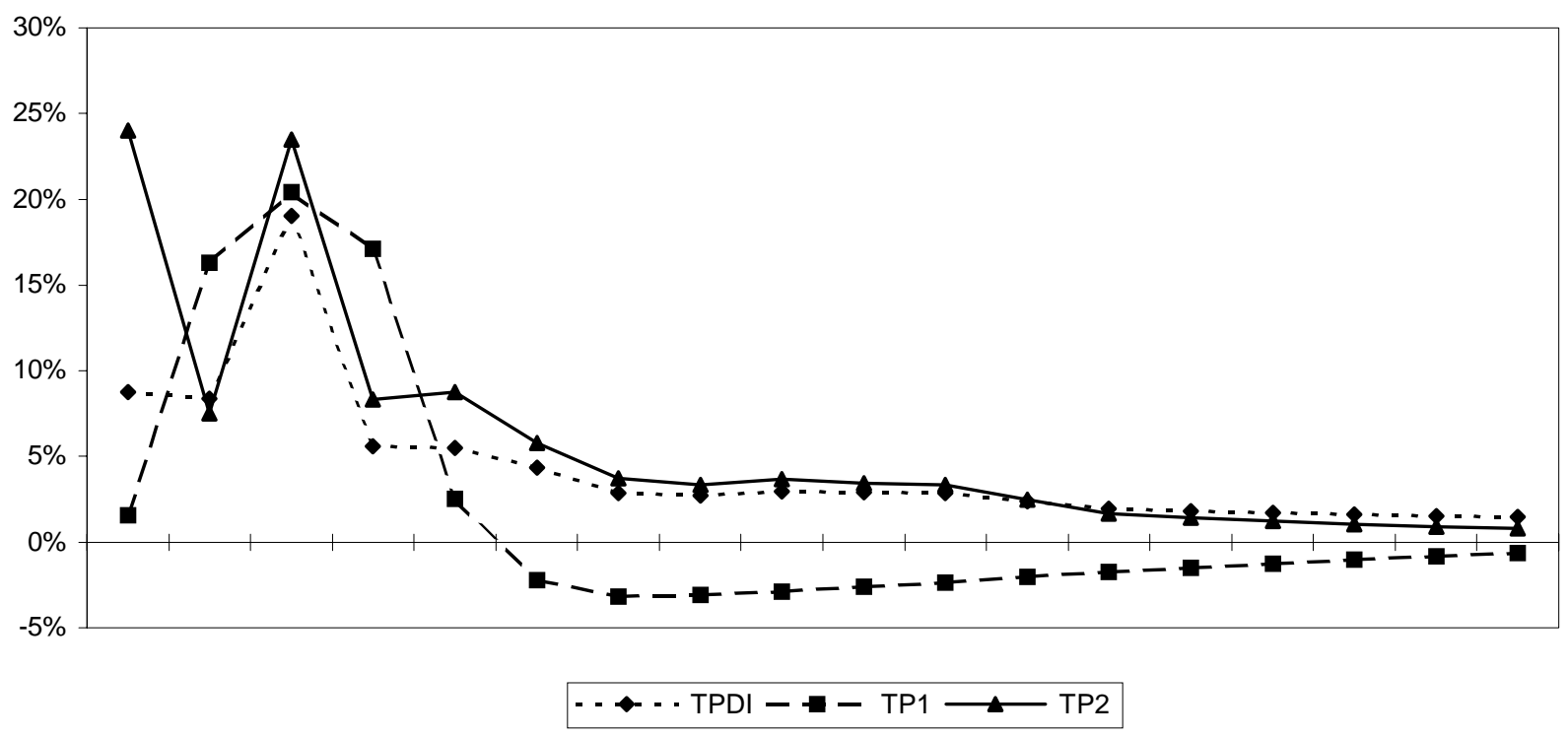


Figure 7: Growth rate of exports from sectors 1 and 2, and imports from sector $2(1993-2010)$

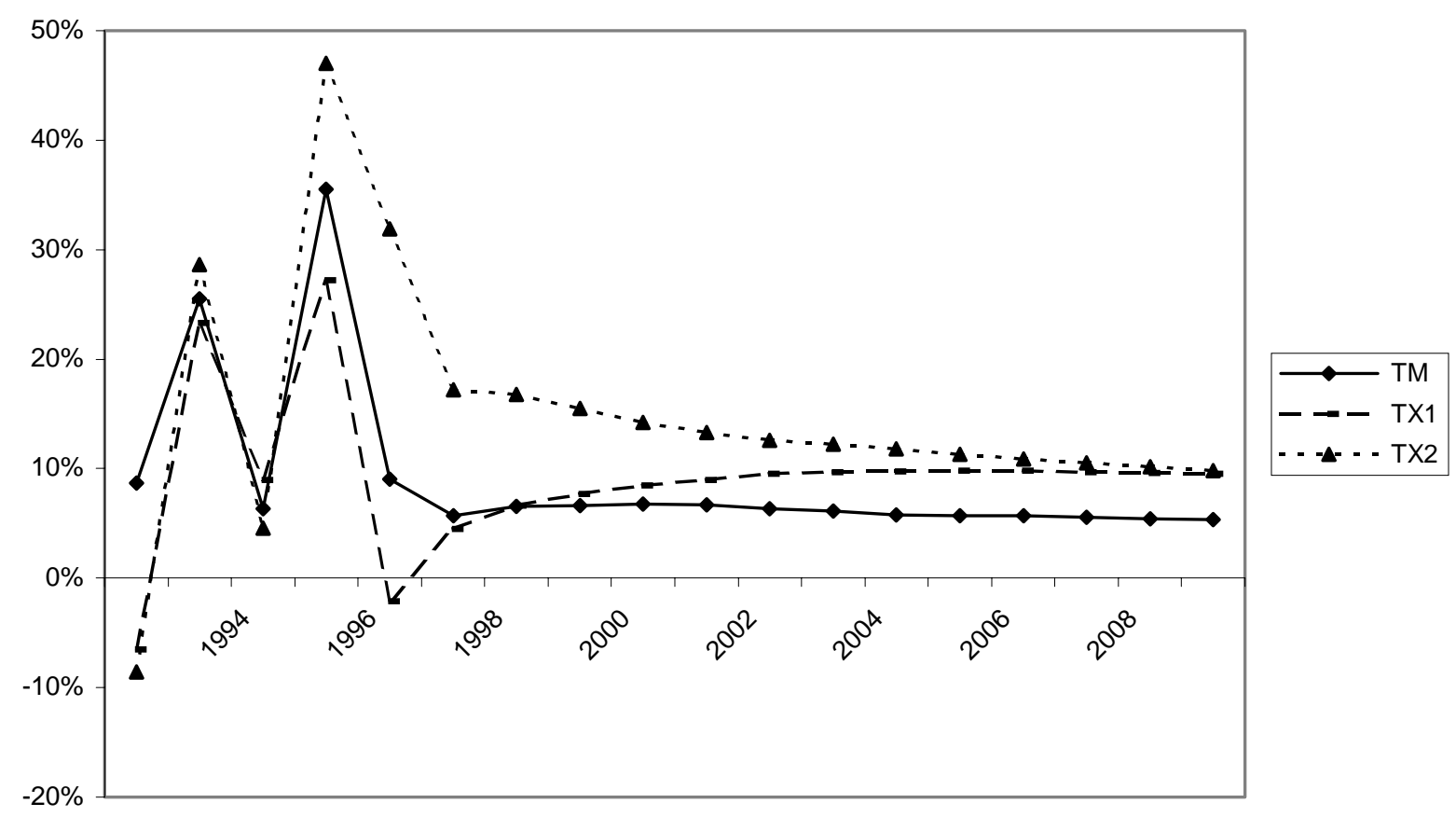

\section{Elementary shocks}

Running elementary projections with shocks allows to analyze model properties. Main numerical results $(X)$ are computed as percentage of variation in relation to the base line path $(X c c)$ - i.e. $\left(\frac{X-X c c}{X c c}\right)$ - except value figures for current accounts and investments, of which the gap against the base line path is referred to the base line path of GDP (GDPCC, in \%), so as to assess distortions in the equilibrium saving/investment, i.e. $\left(\frac{X-X c c}{G D P c c}\right)$.

Various Keynesian mechanisms in an open economy are identified, but the usual behavior of these is heavily impaired by the presence of a supply sector, and the rural-urban migration appears to be an important balancing factor. Thus, the expansionist impact of a demand policy is effective in a first stage. However, after a while, its effects are dampened by the price increases and the bottlenecks in the binding supply sector 1 .

An improvement of supply in the demand sector, such as inputs-saving or an increase in investment, sustains growth due to a higher competitiveness, export promotion and import curbing. But foreign investment is more efficient than domestic investment, due to technology transfers. Finally, wage increases without a simultaneous improvement in supply spurt inflation but do not lead to growth. In the 
same way, a devaluation by itself improves the trade balance but cannot uphold longlasting growth.

The results of three demand-alternative projections are to be found below: a $20 \%$ exchange rate devaluation, a $10 \%$ increase in nominal wages, and a $10 \%$ increase in external demand for product 2 . We add two supply-alternative projections - an increase in foreign direct investment amounting to $3 \%$ of GDP , and a $10 \%$ increase in domestic investment in sector 2.

\section{Demand elementary shocks}

\section{a) A 20\% exchange rate devaluation in 1998}

A devaluation improves competitiveness in sector 2 but, because of import price increases and indexing mechanisms, inflation in the non agricultural sector reaches $9.2 \%$ in the first year. As early as in the third year, competitiveness gains have almost disappeared. However, exports entail a recovery which tends to dampen (+ $5.6 \%$ growth for sector 2 value-added during the first year, but only $2 \%$ after three years). Investment increase follows in sector 2 , while bottlenecks appear in sector 1 , brought by increased foreign and domestic demand. Thus inflation strongly bursts in sector 1 (+15.3\% during the first year and $20 \%$ in the medium term). After a shortlived rise in the beginning, agricultural exports are stagnating. In the short term, the devaluation leads to a shift in income distribution in favor of agriculture, which decreases migration towards the urban sector, but this outcome is short-lived. In spite of the deterioration in terms of trade, the current account improves since the first year following the devaluation, due to volume effects. Finally, devaluation stimulates real GDP and investment growth, but inflation gradually dampens this recovery. This projection illustrates how the usual limits of the exchange rate policy are amplified, as soon as bottlenecks occur in a binding sector. Such structural rigidities prevent the economy from getting ex ante benefits from competitiveness gains.

\begin{tabular}{|c|c|c|c|c|c|c|}
\hline \multicolumn{7}{|c|}{ Table 1: A 20\% Exchange rate devaluation in 1998} \\
\hline TIME & VA & VA2 & PDI & $\mathbf{P 1}$ & $\overline{\mathbf{P} 2}$ & $\mathbf{C M}$ \\
\hline 1998 & 3.82 & 5.56 & 13.25 & 15.28 & 9.24 & 0.24 \\
\hline 2000 & 1.37 & 1.96 & 20.05 & 20.51 & 19.09 & 1.01 \\
\hline 2005 & 0.19 & 0.26 & 20.14 & 20.20 & 19.74 & 0.37 \\
\hline 2010 & 0.61 & 0.80 & 20.11 & 19.54 & 20.13 & 0.58 \\
\hline TIME & W1 & W2U & CHOMPOP & MIG & PRL2DES & UT2 \\
\hline 1998 & 17.04 & 5.16 & 3.21 & 5.92 & 0.13 & 5.56 \\
\hline 2000 & 21.03 & 21.81 & 1.53 & 2.49 & 0.30 & 0.31 \\
\hline 2005 & 20.38 & 21.29 & 0.01 & \begin{tabular}{l|}
0.57 \\
\end{tabular} & 0.11 & 1.35 \\
\hline 2010 & 19.10 & 19.23 & 0.50 & \begin{tabular}{l|l|}
0.66 \\
\end{tabular} & 0.18 & 0.40 \\
\hline TIME & DIFINV & ID2 & DIFBOCV & M2 & $\mathrm{X} 1$ & $\mathrm{X} 2$ \\
\hline 1998 & 4.67 & 13.34 & 1.29 & 2.20 & 5.94 & 3.93 \\
\hline 2000 & 6.01 & 9.50 & 2.85 & 1.55 & 0.86 & 0.67 \\
\hline 2005 & 4.25 & 4.37 & 6.52 & 0.64 & 0.38 & 0.82 \\
\hline 2010 & 4.48 & 4.07 & 7.87 & 0.84 & 0.70 & 0.30 \\
\hline
\end{tabular}




\section{b) A $10 \%$ rise of the urban wage in 1998}

A $10 \%$ rise of the urban wage increases non agricultural prices $(+3 \%$ three years after) but allows for purchasing power gains due to the lag in price adjustments. The initial boom in household consumption is offset by a fall in exports and a rise in imports due to the depletion of competitiveness. Thus the value-added in sector 2 slowly declines $(-1.8 \%$ three years after), while the accelerator effect and the slowing down of investment amplify the recession. In the opposite direction, two forces help to offset the initial shock. The rise of the urban wage strongly stimulates the migration from the rural sector. This migration increases the urban labor supply, and as a result slows the rise in urban wage. In addition, the counterbalancing force played by the share of labor income in value added for the previous period, leads to a wage deceleration. At the end of this adjustment process, the initial shock of the wage increase is almost offset, after a transitory period characterized by a rise of the inflation rate and a declining activity. This projection illustrates the adverse impacts of a shock limited to wage hikes without a simultaneous improvement of the supply side.

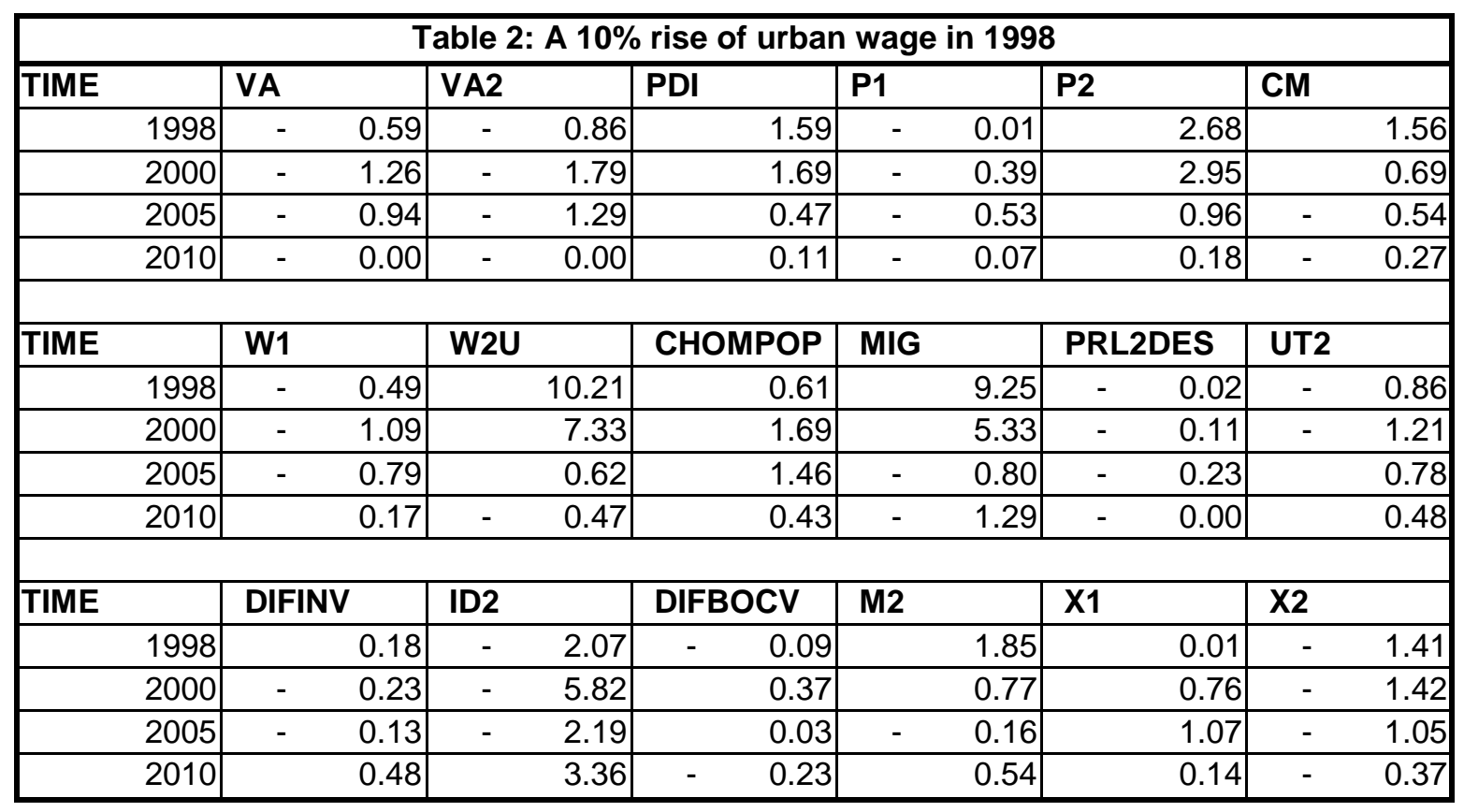

\section{c) A 10\% foreign demand increase in sector 2 in 1998}

A $10 \%$ increase of the foreign demand in sector 2 (equal to $2.7 \%$ of GDP) induces the usual multiplier process through the improvement of exports and the rise of internal demand. The increase of prices and wages slows down this trend and deteriorates the competitiveness. The rigidity of the supply sector leads to an increase of agricultural prices which reduces the agricultural exports. In spite of these adverse effects, the trade balance is strongly improved (around 3\% of GDP in the medium term). The migrations towards the urban sector, induced by the decreasing unemployment and the rise of the relative urban wage, contribute to moderate the wage pressures. The rise of inflation is contained around $2.5 \%$ in the medium term, and the increase of GDP reaches 3\%. 


\begin{tabular}{|c|c|c|c|c|c|c|c|}
\hline TIME & VA & $\overline{\text { VA2 }}$ & PDI & P1 & $\mathbf{P 2}$ & CM & \\
\hline 1998 & 1.82 & 2.65 & 0.87 & 0.75 & 1.43 & & 0.75 \\
\hline 2000 & 2.08 & 2.98 & 1.94 & 1.23 & 3.05 & & 1.53 \\
\hline 2005 & 3.02 & 4.13 & 2.45 & 1.89 & 3.61 & & 3.08 \\
\hline 2010 & 3.11 & 4.07 & 2.56 & 2.12 & 3.70 & & 3.60 \\
\hline TIME & W1 & W2U & CHOMPOP & MIG & PRL2DES & UT2 & \\
\hline 1998 & 1.28 & 0.93 & \begin{tabular}{l|l|}
1.47 \\
\end{tabular} & 1.65 & 0.06 & & 2.65 \\
\hline 2000 & 1.75 & 4.22 & 1.79 & 4.37 & 0.23 & & 1.60 \\
\hline 2005 & 3.35 & 7.53 & 1.58 & 5.26 & 0.52 & - & 0.18 \\
\hline 2010 & 4.66 & 7.70 & $\begin{array}{l}1.15 \\
\end{array}$ & 3.69 & 0.47 & - & 0.08 \\
\hline TIME & DIFINV & ID2 & DIFBOCV & M2 & $\mathrm{X} 1$ & $\mathrm{X} 2$ & \\
\hline 1998 & 0.93 & 6.35 & 1.81 & 3.51 & 1.06 & & 7.50 \\
\hline 2000 & 1.70 & 10.31 & 2.25 & 5.34 & 2.31 & & 6.86 \\
\hline 2005 & 1.76 & 9.16 & 3.73 & 6.39 & 3.68 & & 7.40 \\
\hline 2010 & 1.29 & 4.74 & 4.61 & 6.10 & 4.11 & & 7.28 \\
\hline
\end{tabular}

\section{Supply elementary shocks}

\section{a) A foreign investment increase in sector 2}

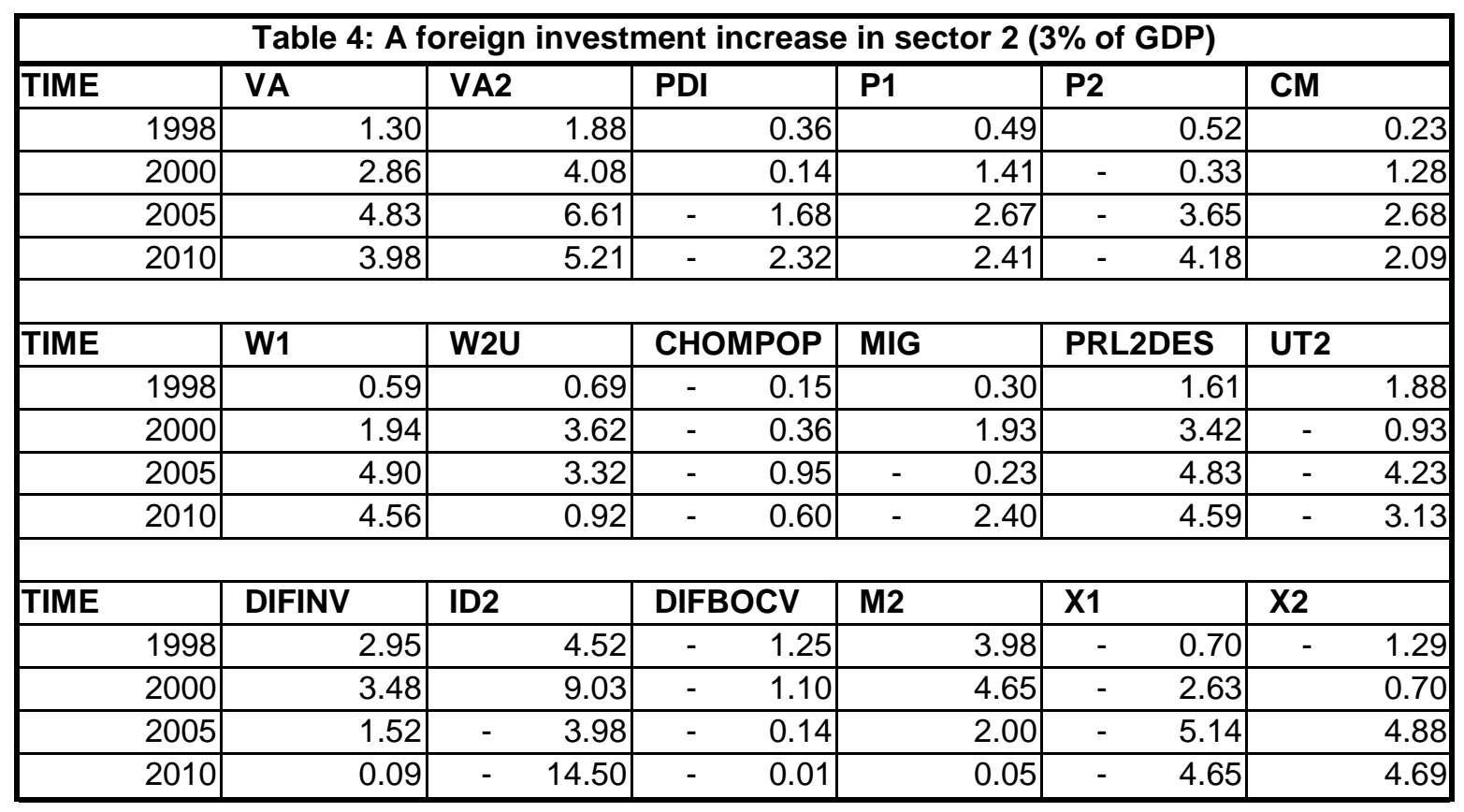

A $36 \%$ increase of foreign investment in the non agricultural sector (equivalent to $3 \%$ of GDP) in 1998 has an impact on the supply side through an improvement of labor and capital productivity due to the introduction of new technologies. The creation of new production capacities and the decrease of production costs lead to a fall of prices in sector 2 and to an improvement of price competitiveness. In consequence, non agricultural exports are boosted. Demand is also stimulated through rising investments, which are partly imported. But in the medium term a higher idle capacity depresses domestic investment. On the whole, GDP increases by $2.9 \%$ after three years and by more than $4 \%$ in the long term, with a slight slowdown of inflation. 
Unemployment decreases but in the short term migration towards the urban sector reduces the pressure on wages. In the agricultural sector, rigidities appear. With the increasing internal demand, agricultural prices rise and exports are reduced. The trade balance is slightly worsened (around $-1 \%$ of GDP), without financing problems as foreign investment rises. This projection highlights, in a rather simplified way, some of the positive effects induced by foreign investments.

\section{b) A domestic investment increase in sector 2}

A $10 \%$ increase in domestic investment in the non agricultural sector (equivalent to $1.4 \%$ of GDP) in 1998 has also an impact on the supply side, but the labor productivity gains are limited and exports of product 2 only increase by around $1 \%$ in the medium term. Production is stimulated through the traditional demand side multiplier (almost $+1 \%$ for the GDP three years later) with a slight deterioration of the trade balance. Unemployment is reduced and the urban wage rate rises, but migration from the rural sector limits the pressure on urban wages. The recovery does not last as excess capacities appear, which curbs the investment boom and leads to an adjustment process. A short term stimulation of the domestic investment in the non agricultural sector has no impact on the long term growth, as the supply effects on productivity are too limited. In this respect a clear difference appears with foreign investment which enables technology transfers and has a larger impact on the potential growth.

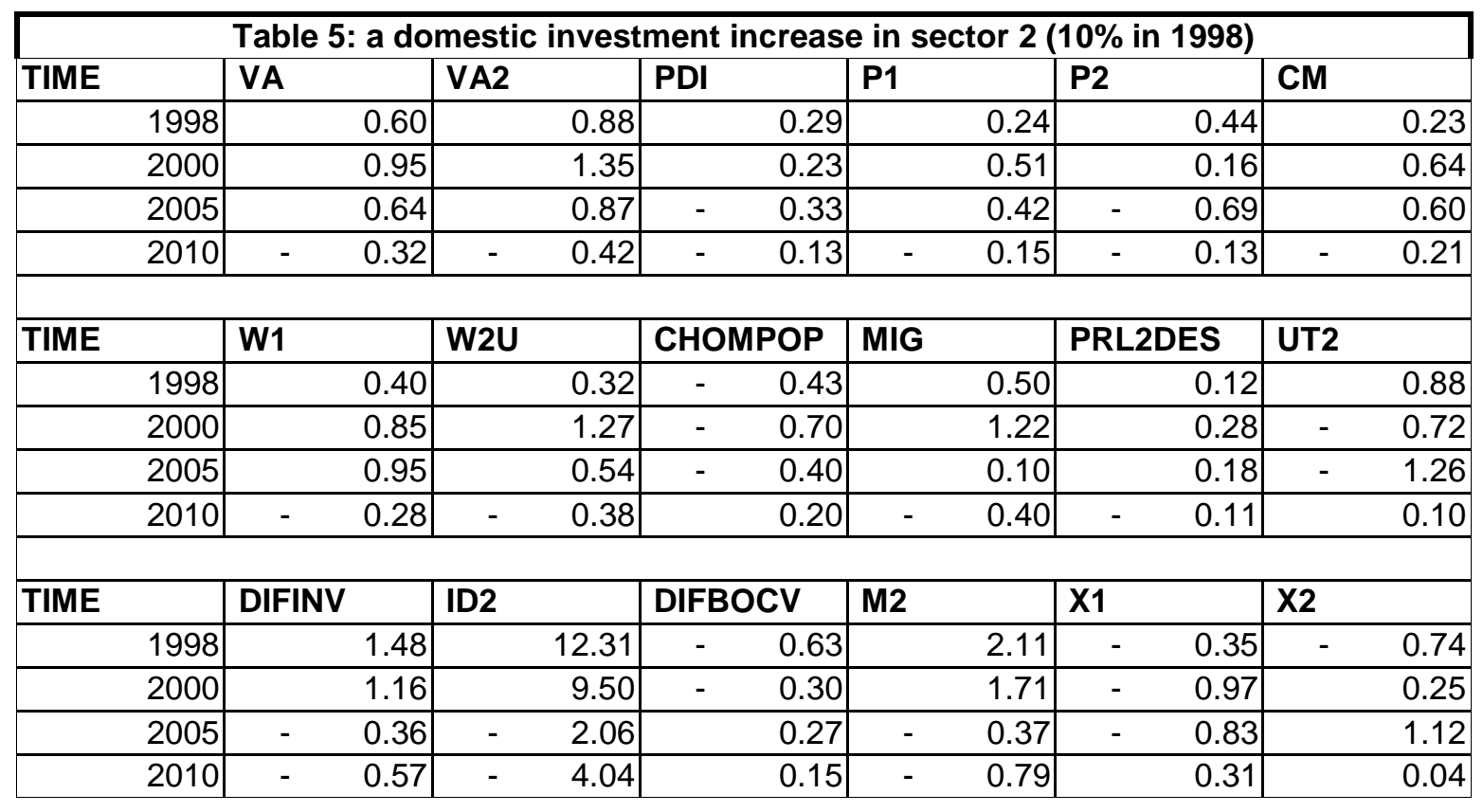

\section{Structural changes and compound shocks}

Three scenarios are built so as to describe structural changes by combining elementary shocks similar to the previous ones. The first scenario illustrates some features of the Asian transition, the second one accounts for the role of foreign investments in the growth strategy followed by the Asian New Industrialized Countries, and the third one assesses some consequences of the Asian crisis for the Vietnamese economy. These scenarios can only describe these complex 
phenomenon's in a very schematic manner, but they outline some dynamic mechanisms in the short and medium terms which seem relevant. The dates used in the base line path and in the scenarios (1998-2010) have no precise meaning regarding the issues analyzed.

\section{The Asian transition}

This projection describes some of the main characteristics of the Chinese and Vietnamese transitions to a market economy (Dodsworth, J.R., and alii, 1996, IMF, 1998):

- a mobilization of domestic savings, particularly by the households;

- a supply policy based on increasing investments and improving efficiency in production methods for both agricultural and non agricultural sectors, especially through extensive reforms and the improvement of productivity in agriculture;

- the relative success in price stabilization while maintaining output growth (Kalra, S., and Slok, T., 1999).

A combination of domestic saving and capital accumulation without significant foreign investment has also been pointed out in some Asian emerging countries characterized by a long-lasting steady growth, such as South Korea .

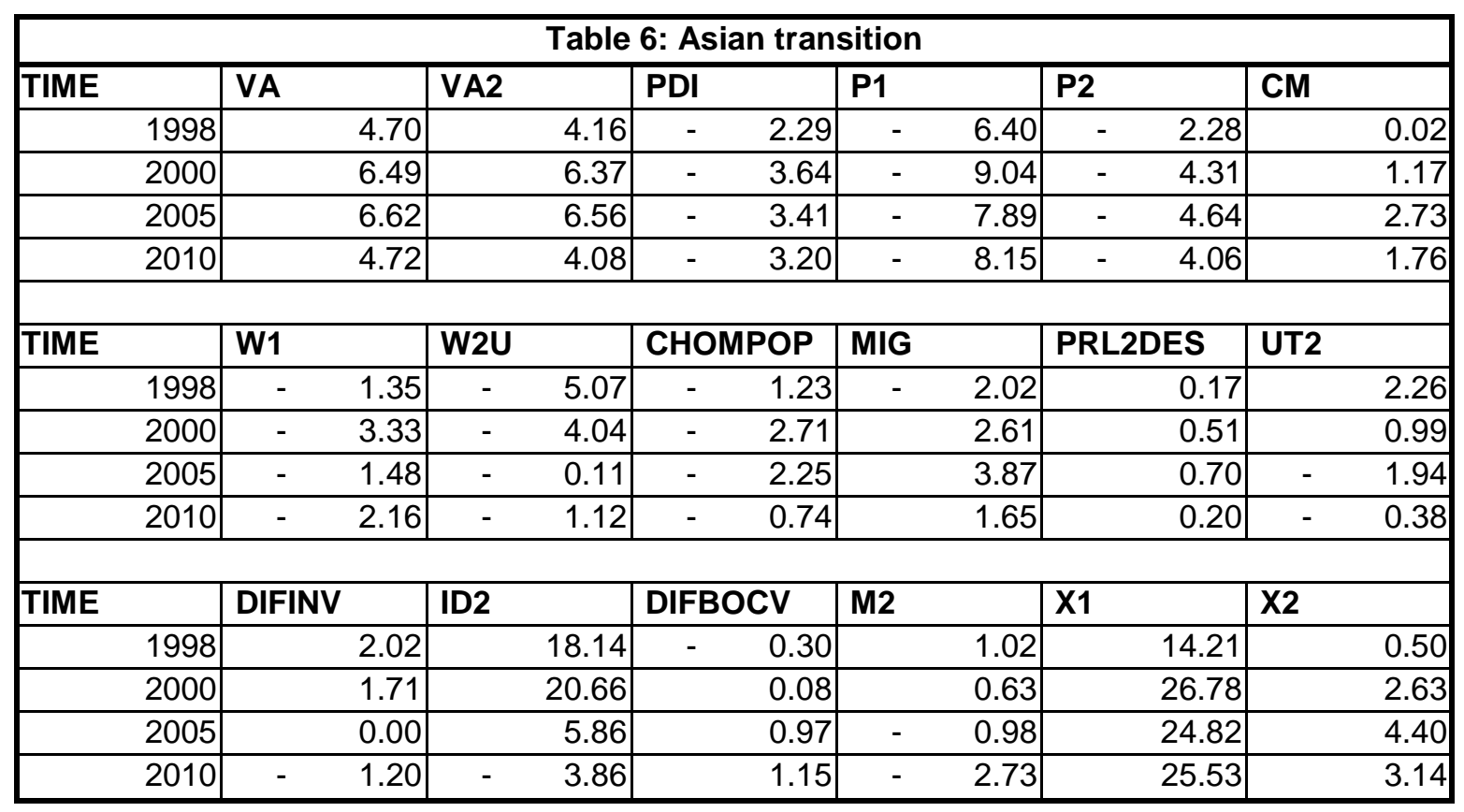

More precisely speaking, we have modified the base line path by introducing the following additional factors starting in 1998:

- a 10\% rise of domestic investment in both sectors 1 and 2;

- a $10 \%$ rise in the households' saving rate;

- a $2 \%$ fall in intermediate consumption of both sectors 1 and 2, so as to account for the modernization effort;

- a $5 \%$ rise of capital productivity in the agricultural sector, for the same reason; 
- a $5 \%$ decrease of urban wages to account for the fact that productivity gains are not distributed to the workers and are used to improve competitiveness.

This projection combines four kinds of mechanisms :

- The rising accumulation rate in both sectors contributes to the loosening of supply constraints and stimulates the demand addressed to the non agricultural sector. Because agricultural producers operate at 100 per cent of capacity, production capacity improve in sector 1 has a greater impact on growth than such an increase in sector 2 , reducing inflationary pressures.

- The households' saving rate rises, which helps to finance increasing investment without the contribution of external savings. On the other hand, it curbs down household consumption, which only increases moderately, in spite of the recovery.

- Higher labor productivity in sector 2 and capital productivity in sector 1, combined with savings in intermediate consumption, improve economic competitiveness. Progress in exports, and especially in agricultural exports, offsets the deterioration of the terms of trade.

- Finally, unemployment decreases, but urban migration limits the wage pressures.

On the whole, growth is rather strongly stimulated (GDP increases by $+6.5 \%$ three years after the beginning of the period). This extra growth is mainly pulled by investment and foreign trade, and the current balance is slightly improving in the medium term. The rise in the saving rate limits household consumption, which share in total GDP declines. Productivity gains and the loosening of production capacities entail a fall in prices in both sectors $(-3.6 \%$ after three years, for the domestic demand price).

This projection outlines how a combination of significant saving effort, high accumulation rate and productivity gains generates a foreign trade and investmentled growth. The role played by the modernization of agriculture is also highlighted. A rising domestic saving rate helps to finance investments without pressures on the current account. Lastly the successful disinflation policies during the transition period in countries like Vietnam or China seem to be linked to the capacity of promoting supply.

\section{FDI and modernization}

Unlike the previous projection, extra investment comes from foreign direct investments (FDI). It does not create financing problems thanks to foreign saving. But only the non agricultural sector is concerned by the modernization effects in labor productivity and input savings. Such a scenario loosely outlines the strategy followed by many Asian emerging countries since the 1980's (the more recent NICs, i.e. "Asian tigers"). It can also catch some features of the Chinese strategy which has attracted a large amount of FDI to promote manufacturing exports since the end of the 1980's. In this sense, it is possible to combine this scenario with the previous one so as to get a more comprehensive understanding of the Chinese case.

We have modified the base line path by introducing the following additional factors starting in 1998: 
- a rise in FDI equivalent to $3 \%$ of GDP;

- a $2 \%$ fall in the input of sector 2 ;

- a decrease of $-5 \%$ of the urban wage to account for the fact that the productivity gains are used by the firms to improve their competitiveness, and are not distributed to the wage-earners.

\begin{tabular}{|c|c|c|c|c|c|c|c|c|c|c|c|}
\hline TIME & \multicolumn{10}{|c|}{\begin{tabular}{l|l|l|l} 
Table 7: "Asian tigers model" (modernization by FDI) \\
VA2
\end{tabular}} & \\
\hline 1998 & 3. & & 4.47 & - & 1.24 & & 0.05 & - & 2.05 & - & 0.34 \\
\hline 2000 & 5. & & 8.02 & - & 2.04 & & 1.21 & - & 3.87 & & 1.38 \\
\hline 2005 & 7. & & 10.83 & - & 3.36 & & 2.79 & - & 6.40 & & 4.05 \\
\hline 2010 & 6. & & 8.49 & - & 4.00 & & 2.17 & - & 6.71 & & 3.48 \\
\hline TIME & W1 & & $\overline{W 2 U}$ & $\mathrm{CHC}$ & DOP & MIC & & PRL & $\overline{E S}$ & UT2 & \\
\hline 1998 & 0. & & 4.60 & - & 0.58 & . & 4.19 & & 1.65 & & 2.56 \\
\hline 2000 & 2 & & 1.01 & - & 1.84 & . & 0.94 & & 3.57 & & 0.13 \\
\hline 2005 & 5. & & 2.78 & - & 2.57 & & 0.53 & & 5.16 & - & 4.70 \\
\hline 2010 & 5. & & 0.90 & - & 1.58 & & 1.62 & & 4.76 & - & 3.40 \\
\hline TIME & DIFINV & & D2 & DIF & & M2 & & $\mathrm{X} 1$ & & $\mathrm{X} 2$ & \\
\hline 1998 & 2. & & 8.11 & - & 1.02 & & 1.82 & - & 0.08 & & 0.19 \\
\hline 2000 & 3. & & 16.31 & - & 1.24 & & 2.94 & - & 2.28 & & 2.73 \\
\hline 2005 & 1. & & 0.48 & - & 0.15 & & 0.76 & - & 5.35 & & 7.29 \\
\hline 2010 & 0. & & 15.28 & & 0.12 & 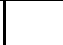 & 1.96 & - & 4.20 & & 6.82 \\
\hline
\end{tabular}

This scenario is based on three main mechanisms :

- The additional investment in sector 2 entails a GDP recovery due to the Keynesian multiplier, while it loosens the pressures on production capacity.

- The price fall in sector 2 it causes is amplified by productivity gains in labor and inputs, due to the transfer of new technologies. Thanks to price competitiveness improvement, exports soar and strengthen growth without requiring excessive imports. But contrary to the previous case, supply rigidities in the agricultural sector are gradually binding. Prices hikes in this sector curb disinflation and reduce competitiveness gains.

- Unemployment is scaled down, but the migration towards the urban sector remains limited or even diminishes due to the improvement of agricultural income per capita.

On the whole, these factors entail an increasing expansion ( $8 \%$ for the GDP in the medium term). The decrease of the demand price index speeds up with time $(-4 \%$ in the medium term) in spite of the rise of agricultural prices. But contrary to the former case, consumers take wholly advantage of the expansion, due to the increase in income. Thus, growth is pulled by investment, consumption and exports. In the medium term, decreasing pressures on production capacities curb the investment boom, thus stabilizing the growth rate. Pressures on trade balance are curbed by competitiveness gains and the current account deficit does not exceed $-1.2 \%$ of GDP, which is easily compensated by foreign saving. Finally, putting aside the drawbacks of foreign investment, this scenario pictures a regime of balanced growth. 


\section{The impact of the Asian crisis}

Some real aspects of the impact of the Asian crisis on the Vietnamese economy can be simulated in our framework. In comparison with the baseline path, the Asian crisis induces three consequences which are introduced as shocks:

- The foreign demand addressed to the non agricultural sector is reduced by $10 \%$;

- FDI are reduced by $36 \%$, i.e. about $3 \%$ of GDP. In consequence, transfers of technology are weaker, involving less productivity improvements in the non agricultural sector. For the same reason we introduce an increase in input consumption of $2 \%$ in sector 2 .

-The Asian crisis induces a devaluation of the dong fixed at $20 \%$. This last shock is dealt with in another forecast, in order to isolate its effects.

We first consider the impact of the Asian crisis on the Vietnamese economy without taking the devaluation into account (table 8). In a second stage we introduce the additional impact of the devaluation (table 9).

\begin{tabular}{|c|c|c|c|c|c|c|c|c|c|c|c|c|}
\hline \multicolumn{13}{|c|}{ Table 8: Asian crisis 1} \\
\hline TIME & $\overline{\text { VA }}$ & & $\overline{\mathrm{VA}^{\prime}}$ & & PDI & & $\overline{\mathbf{P 1}}$ & & $\mathbf{P 2}$ & & $\mathbf{C M}$ & \\
\hline 1998 & - & 4.57 & - & 6.64 & - & 0.57 & - & 0.85 & . & 0.90 & - & 1.26 \\
\hline 2000 & - & 6.78 & - & 9.69 & - & 0.98 & - & 2.22 & . & 0.85 & - & 3.22 \\
\hline 2005 & - & 10.30 & - & 14.09 & & 0.83 & - & 4.29 & & 3.15 & - & 6.49 \\
\hline 2010 & - & 9.88 & - & 12.93 & & 1.80 & - & 4.39 & & 4.11 & - & 6.77 \\
\hline TIME & W1 & & W2 & & $\mathrm{CHC}$ & DOP & MIG & & PR & & \begin{tabular}{|l|l} 
UT2 \\
\end{tabular} & \\
\hline 1998 & - & 1.61 & - & 1.53 & & 1.84 & - & 2.45 & 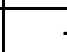 & 1.70 & - & 4.87 \\
\hline 2000 & - & 3.58 & - & 7.36 & & 2.66 & - & 6.74 & & 4.00 & - & 1.16 \\
\hline 2005 & - & 8.58 & - & 10.73 & & 3.27 & - & 5.88 & + & 6.38 & & 5.28 \\
\hline 2010 & - & 9.98 & - & 8.60 & & 2.35 & - & 1.39 & & 6.42 & & 3.97 \\
\hline TIME & DIFI & & ID2 & & DIFE & & M2 & & $\mathbf{X 1}$ & & $\mathrm{X} 2$ & \\
\hline 1998 & - & 4.00 & - & 13.51 & - & 0.74 & - & 6.49 & & 1.23 & - & 7.14 \\
\hline 2000 & - & 5.18 & - & 22.16 & - & 1.19 & - & 8.75 & & 4.40 & - & 8.93 \\
\hline 2005 & - & 3.41 & - & 9.09 & - & 3.47 & - & 7.16 & & 9.16 & - & 14.17 \\
\hline 2010 & - & 1.27 & & 6.70 & - & 4.47 & - & 4.58 & & 9.40 & - & 14.19 \\
\hline
\end{tabular}

Excluding devaluation, the main mechanisms are the following. The decrease in foreign demand leads to a recession with a fall in GDP and in prices and a slight deterioration of the current account in the medium term. The drop in FDI amplifies the slowing down, but does not additionally worsen the current account. The efficiency of the non agricultural sector is affected by both productivity losses and increasing input consumption. As a result non agricultural prices increase and competitiveness worsens, adding to the slowing down. In the long term a stabilization effect appears as idle capacities decrease, inducing a recovery of investment.

The overall result is a dramatic and increasing recession $(-4.5 \%$ in the short term and $-10 \%$ in the medium term for the GDP), mainly due to the decrease of both investment and exports of non agricultural goods. The price changes are strongly differentiated, with a rise of non agricultural prices in the medium term, due to the productivity decline, and a fall of agricultural prices, due to the decrease in demand. 
Finally the acceleration of inflation remains moderate $(+1 \%$ in the medium term). Finally, unemployment increases, but the strong reduction of the migration towards urban sector limits this increase. Agricultural exports, insensitive to foreign demand, can grow with the decrease of prices. Current account is deteriorating since the first year due to the contraction of non agricultural export and of export prices.

\begin{tabular}{|c|c|c|c|c|c|c|c|}
\hline \multicolumn{8}{|c|}{ Table 9: Asian crisis 2.} \\
\hline TIME & VA & VA2 & PDI & $\mathbf{P 1}$ & $\mathbf{P 2}$ & $\mathbf{C M}$ & \\
\hline 1998 & 0.99 & 1.44 & 12.53 & 14.18 & 8.22 & - & 1.48 \\
\hline 2000 & 5.60 & 8.00 & 18.91 & 17.71 & 18.15 & 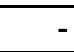 & 2.28 \\
\hline 2005 & 10.17 & 13.92 & 21.15 & 14.99 & 23.55 & - & 6.19 \\
\hline 2010 & 10.47 & 13.70 & 22.32 & 14.31 & 25.17 & 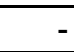 & 7.30 \\
\hline TIME & W1 & W2U & CHOMPOP & MIG & PRL2DES & UT2 & \\
\hline 1998 & 14.98 & 3.56 & 1.29 & 8.12 & 1.58 & & 0.43 \\
\hline 2000 & 16.51 & 13.15 & 1.25 & 4.07 & 3.73 & & 1.52 \\
\hline 2005 & 9.98 & 8.33 & 3.33 & 5.29 & 6.31 & & 3.92 \\
\hline 2010 & 7.20 & 9.04 & 2.91 & 2.09 & 6.59 & & 4.43 \\
\hline TIME & DIFINV & ID2 & DIFBOCV & M2 & $\mathrm{X} 1$ & $\mathrm{X} 2$ & \\
\hline 1998 & 0.04 & 0.91 & 0.52 & 8.52 & 7.43 & 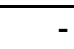 & 3.48 \\
\hline 2000 & 0.43 & 14.29 & 1.51 & 7.41 & 3.70 & - & 8.33 \\
\hline 2005 & 0.21 & 13.04 & 2.29 & 7.75 & 8.84 & - & 13.51 \\
\hline 2010 & 2.99 & 2.89 & 2.50 & 5.36 & 10.13 & - & 14.51 \\
\hline
\end{tabular}

With a devaluation of $20 \%$ of the dong, the results are rather different. The specific effect of the devaluation is an expansion in the short term, followed by an acceleration of inflation which dampens progressively the recovery. Pressures also appear on agricultural prices due to increasing demand. These effects improve the trade balance.

Combining these results with the previous ones, we can complete the picture of the impact of the Asian crisis on the Vietnamese economy. The devaluation alleviates the short term recessive effects through its favorable impact on exports. But this positive influence weakens with increasing inflation (+18.9\% after three years). The investments in the non agricultural sector are more preserved in the short term. The bottlenecks in agriculture lead to an increase of prices which constrains exports. Current account improves (around $+1.5 \%$ of GDP). On the whole, in spite of the balancing effect of the devaluation, the impact of the Asian crisis in its real dimension remains very negative, with a sharp decline of the GDP (-5.6\% after three years) and of the investments, and with an increasing inflation which is mainly due to the specific effects of the devaluation. The unemployment rises but the reduction of the migration has a stabilizing effect.

\section{Conclusion}

We have presented a fairly simple two-sector model including an agricultural sector with a rigid supply and a demand-led sector. In addition to the gradual price adjustment between supply and demand in the agricultural sector, it includes a complete description of the input-output relations and an overall analysis of the dynamic of prices and wages. Urban migration depends on the relative rural-urban 
income and on the unemployment level, and appears as an important adjustment factor. International opening up and investment behavior are introduced in both sectors, with a differentiated impact of domestic or foreign investment on productivity due to the introduction of new technologies in the case of FDI. The model has given a first set of results.

Analytical simulations with elementary supply and demand shocks have been used to get a better understanding of the model properties and to check its sensitivity to the main parameters. Besides Keynesian mechanisms in an open economy, rigidities in the supply sector exert a strong influence. A change in the rate of rural-urban migration is a balancing factor: it can lessen the wage pressures or, in the case of a slowdown (due to market adjustment or to administrative enforcement), it may scale down the level of urban unemployment. Here the model replicates the relative rigidity of Vietnamese migrations (O'Connor, D., 1998). More labor mobility could cause more dramatic effects, except in the case of balanced development policy in the non urban area (on this point, the success of the Chinese experience would be more enlightening).

As usual, a stimulation of demand leads to a recovery, but this effect is dampened by the increasing capacity utilization, the price rises and the bottlenecks in the binding supply sector. An improvement of supply in the demand sector, such as inputs saving or an increase in investment, promotes growth due to productivity gains and higher competitiveness. But foreign investment has a larger impact than domestic investment. Moreover, a rise in capital productivity is more efficient in the supply sector than in the demand sector. Lastly, wage increases without simultaneous supply improvements create inflation and do not lead to additional growth. Similarly, a devaluation alone improves the trade balance but cannot sustain long-lasting growth.

A second set of simulations using compound shocks has explored three kinds of structural change. It has allowed to outline some issues which Vietnam has (or had) to face, and to make comparisons with growth strategies experimented in other Asian countries:

- Some of the main characteristics of the Chinese and Vietnamese transitions to a market economy has been described. The combination of a significant saving effort, a high rate of accumulation and productivity gains generates a foreign trade and investment-led growth without worsening the current account. Unemployment decreases, and the urban migration lessens the wage pressures. The rather successful disinflation policies are linked with the capacity of promoting supply. The role played by agriculture modernization is highlighted.

- The role of FDI in modernizing the productive system has been analyzed so as to sum up the strategy followed by the Asian tigers. It also catches some features of the Chinese strategy of attracting FDI so as to promote manufacturing goods exports. Due to the increase of investment and to productivity gains, a regime of balanced growth can be achieved, with an improvement in competitiveness and a restrained current deficit. Contrary to the former case, consumption is also sustained due to the increase in incomes.

- Some real aspects of the impact of the Asian crisis on the Vietnamese economy have been simulated. The decrease of foreign demand and the decline of FDI have a negative impact in terms of a sharp decline of GDP and of investment, in spite of the balancing effect of the devaluation of the dong. The decrease of urban migration limits the magnitude of the increase in unemployment. The increasing inflation is mainly due to the effects of the devaluation. 
Thus, this model emphasizes the strong effect of domestic and foreign capital accumulation, productivity growth, and opening up. It highlights some consequences of demographic dynamics and internal migrations. However, it deals neither with financial and monetary issues, nor with the crucial questions of the efficiency of a "developmental state", and public sector reforms (Crafts, N., 1999). Modeling financial transformations and internal liberalization will be the next step of this work.

\section{References:}

- Agenor Pierre.Richard. and Montiel, Peter.J., Development Macroeconomics, Princeton, N.J.: Princeton University Press, $2^{\text {nd }}$ ed.1999, .

- Basu, Kaushik., Analytical Development Economics: the Less Developed Economy Revisited, Cambridge, Ma.: MIT Press, 1997.

- Cardoso, Eliana, "Food supply and inflation", Journal of Development Economics, 8:269-84. June,1981.

- Crafts, Nicholas., "East Asian Growth Before and After the Crisis", Washington

D.C.: IMF Staff Papers, Vol. 46, n²,.., pp.139-166. June, 1999.

- Dodsworth, John., R., and alii, "Vietnam, transition to a Market Economy", IMF Occasional Paper n¹35. Washington DC, March, 1996.

- General Statistical Office of S.R.V.N., Statistical Yearbook, Hanoi, RDVN: GSO, 1999.

- Harris, John., and Todaro, Michael.P., Migration, unemployment and development: a two sector analysis, American Economic Review 60:126-142, March 1970.

- IMF, Vietnam: Selected Issues and Statistical Annex, IMF Staff Country Report n.98/30, Washington D.C., IMF, 1998,.

- IMF, Vietnam: Statistical Appendix, IMF Staff Country Report n.99/56 Washington D.C., IMF, 1999,.

- Kalecki, Michael., Essays on developing economics. Hassocks, U.K.: Haverster Press, 1976.

- Kalra, Sanjay., and Slok, Torsten., Inflation and growth in transition: are the Asian economies different?, IMF Working Paper, WP/99/118, Washingon D.C., IMF, 1999. - Krugman, Paul. and Taylor Lance, " Contractionary effects of devaluation", Journal of International Economics, (8), pp.445-56, August, 1976.

- Lavigne, Marie, 1999, Economie du Vietnam, réforme, ouverture et développement. Paris: Coll. Pays de l'Est, L'Harmattan,. 1999.

- Le Van Cuong, and Mazier, Jacques, (eds.). L'Economie vietnamienne en transition, les facteurs de la reussite. Paris: Coll. Pays de l'Est, L'Harmattan, 1998, - Le Van Cuong., and Mazier, Jacques, (eds.). L'Economie vietnamienne et la crise asiatique, Paris. L'Harmattan, 1999.

- O'Connor, David, Rural industrial development in VienNam and China, a study in contrasts, Technical Paper n¹40, Paris: OECD Development Centre, September, 1998.

- Ranis, Gustav, "Analytics of Development: Dualism", in H.Chenery, and T.N.

Srinivasan, Eds. Handbook of Development Economics, Vol.1, pp.73-93,Amsterdam :North Holland, 1989,

- Rattso, Jorn, "Macrodynamic Adjustment Mechanisms in a Dual Semi-industrialised Economy", Journal of Development Economics, 30(1):47-69, 1989.

- Ray Debraj, Development Economics. Princeton, N.J.: Princeton University Press. 
- Sand-Zantman, Alain, Le Tiers-Monde: les stratégies de développement à l'épreuve des faits. Paris: Hatier, $2^{\text {nd }}$ ed. 1991.

- Sand-Zantman, Alain, and alii, Transition and development in Asia: a medium range model for structural changes and external shocks impacts analysis applied to the Vietnam Case, Document Erudite n`99-04, La Varenne, Université Paris XII, 1999a.

- Sand-Zantman, Alain and alii, Les enseignements d'un modèle à deux secteurs pour l'économie vietnamienne, in C.Le Van and J. Mazier, eds., L'Economie vietnamienne et la crise asiatique, p.273-297, Paris. L'Harmattan, 1999b.

- Taylor, Lance., Structuralist Macroeconomics, New York: Basic Books. 1983.

- Taylor, Lance, Income Distribution, Inflation, and Growth, Cambridge, Ma.:The MIT Press, 1991.

\section{Mnemonics:}

\section{1) Exogenous variables listing and parameters values of the model:}

Prices, nominal wage and exchange rate indexes are computed using 1989=100 as base.

\section{1.) Exogenous variables and main parameters listing:}

$\bar{\delta}_{1}$ : depreciation rate of capital stock in agricultural sector,

$\bar{\delta}_{2}$ : depreciation rate of capital stock in non agricultural sector,

$\bar{\chi}_{1}$ : inverse of capital output ratio in agricultural sector,

$\bar{\lambda}_{1}:$ accumulation rate in agricultural sector,

$\gamma_{k}^{f}$ : elasticity of capital productivity increase to foreign part of sector 2 accumulation.

$\gamma_{l}^{f}$ : elasticity of labor productivity increase to foreign part of sector 2 accumulation.

$\gamma_{l}^{d}$ : elasticity of labor productivity increase to domestic part of sector 2 accumulation.

$\overline{i e_{2}}$ : F.D.I. in non agricultural sector,

$c \bar{w}:$ propensity to consume of sector 2 labor incomes,

$c \bar{R}$ : propensity to consume of other incomes,

$\eta_{1}$ : good 1 consumption elasticity to discretionary consumption budget,

$\eta_{2}$ : good 1 consumption elasticity to relative prices.

$\overline{c g z}$ : public expenditures,

$\bar{a}_{i j}:$ technical (Leontief) coefficients,

$\overline{p e t}$ : foreign price in foreign currency,

$\overline{d o n g}$ : exchange rate,

$\overline{u_{2} \max }$ : maximum capacity utilization rate in non agricultural sector,

$\varepsilon x_{1}$ : real exchange rate elasticity of agricultural exports,

$\varepsilon x_{2}$ : real exchange rate elasticity of non agricultural exports,

$\varepsilon u \times 2$ : elasticity of exports to a change in utilization rate of production capacity,

$\varepsilon m_{2}$ : real exchange rate elasticity of non agricultural imports,

Eum 2 : elasticity of imports to a change in utilization rate of production capacity,

$\xi_{1}$ : wage indexing on inflation,

$\xi_{2}$ : sensibility of urban wage to unemployment rate,

$\xi_{2}$ : sensibility of urban wage to the functional distribution in urban area, 
$\psi$ : elasticity of migrations to expected urban/rural wage differential,

$v_{1}$ : sensibility of sector 2 production distribution between urban and rural areas to urban/rural wage ratio,

\section{2) Main parameters values:}

Investment parameters in sector $2: \lambda_{20}=.8, \lambda_{21}=.1, \lambda_{22}=.1, \lambda_{23}=.015$

Trade elasticity/real exchange rate : $\varepsilon x_{1}=2, \varepsilon x_{2}=.7, \varepsilon m_{2}=-.7$,

Trade elasticity/utilization capacity rate : $\varepsilon u x_{2}=-.5, \varepsilon u m_{2}=.2$,

Capital productivity increase $: \gamma_{k}^{f}=.018405$.

Labor productivity increase: $\gamma_{l}^{f}=.175, \gamma_{l}^{d}=.075$,

Global consumption budget: $\overline{c w}=.95,: \overline{c R}=.7$,

Consumption of product 1: $\eta_{1}=.7, \eta_{2}=-.2, \overline{c m_{1}}=7200$;

Urban wage : $\xi_{1}=.3, \xi_{2}=.3, \xi_{3}=.5, \varpi=.2$,

Migration : $\psi=.7$

Distribution of sector 2 production between urban and rural areas: $v_{1}=-.05, v_{2}=.8$, $v_{3}=-.10, v_{4}=.2$,

\section{2) Ex-post and ex-ante projections: endogenous variables listing:}

\section{1) base line projection}

ti :growth rate of total investments,

ti1 : growth rate of investments in sector 1 ,

ti2 : growth rate of investments in sector 2 ,

tpdi : inflation rate (general price index of domestic demand),

tp1 : inflation rate in agricultural sector (output / consumption price index),

tp2 : inflation rate in non agricultural sector (domestic output price index),

tx1 : growth rate of exports (agricultural sector)

tx2 : growth rate of exports (non agricultural sector),

tm2 : growth rate of imports (non agricultural sector),

tva : growth rate of real GDP,

tva1: growth rate of real value added in sector 1 ,

tva2 : growth rate of real value added in sector 2 ,

\section{2) Alternatives scenarios:}

Except special indication (noted *), data give the \% change of alternative projections over base line simulation.

va : real GDP,

va2 : real value added in sector 2 ,

pdi : general price index of domestic demand,

p1 : output / consumption price index,

p2 : domestic output price index in non agricultural sector,

cm : households real global consumption,

w1 (= w2c): rural income,

w2u : urban labor income,

chompop: ratio of difference between unemployment in both alternative and base line projection, over baseline urban active population (\%),

mig: migrations between rural/urban areas, 
prl2des: targeted labor productivity rate,

ut2: utilization capacity in sector 2 ,

difinv : ratio of difference between total investments in both alternative and base line projections, over baseline GDP,

id2 : domestic investments in sector2,

difbocv : ratio of difference between trade balances in both alternative and base line projections, over baseline GDP (all variables in value)

$\mathbf{x 1}$ : exports of agricultural sector,

$\mathbf{x} 2$ : exports of non agricultural sector,

m2 : imports of non agricultural sector. 